\title{
Genetic Transformation in Aromatic Indica Rices Mediated by Agrobacterium tumefaciens
}

\author{
N. Aananthi ${ }^{1 *}$ and C.R. Anandakumar ${ }^{2}$ \\ ${ }^{1}$ Department of Plant Breeding and Genetics, AC \&RI, TNAU, Killikulam, India \\ ${ }^{2}$ Tamil Nadu Agricultural University, Coimbatore, Tamil Nadu, India \\ *Corresponding author
}

\begin{tabular}{l}
$\begin{array}{l}\text { K e y w or d s } \\
\text { Agrobacterium, Aromatic } \\
\text { indica rices, Genetic } \\
\text { transformation, immature } \\
\text { embryos }\end{array}$ \\
\hline Article Info \\
\hline $\begin{array}{l}\text { Accepted: } \\
\text { 24 November } 2018 \\
\text { Available Online: } \\
10 \text { December } 2018\end{array}$ \\
\hline
\end{tabular}

A B S T R A C T

Aromatic rice is profitable farming venture and having high consumer demand. The main concerns about aromatic rice are low yield and susceptibility to pests and diseases. A rapid and reproducible genetic transformation protocol was optimized for three aromatic rice varieties using the established plant regeneration protocol. Mature embryos were inoculated with Agrobacterium tumefaciens strain EHA 105 carrying binary vector pCAMBIA 1305.1 with GUS (reporter gene) and hpt (hygromycin resistance) gene and the transformation experiment was performed by optimizing the parameters infection time and co cultivation periods. Callus induction was obtained when the seeds namely Pusa Basmati 1, (58.6\%) Pusa Sugandh 4(56\%) and Pusa Sugandh 5 (55.6\%) were cultured on MS medium supplemented with $2.5 \mathrm{mg} \mathrm{l}^{-1} \mathrm{IAA}+0.5 \mathrm{mg} \mathrm{l}^{-1}$ kinetin $+1.0 \mathrm{gl}^{-1} \mathrm{CH}+30 \mathrm{~g} \mathrm{l}^{-1}$ maltose $+100 \mathrm{ml}^{-1}$ coconut milk and gelled with agar under dark condition. Maximum regeneration was obtained with MS supplemented with $2.5 \mathrm{mg} \mathrm{l}^{-1} \mathrm{BAP}+0.5 \mathrm{mg} \mathrm{l}^{-1} \mathrm{~K}+$ $1.0 \mathrm{mg} \mathrm{l}^{-1} \mathrm{~K}+1.0 \mathrm{gl}^{-1} \mathrm{CH}+30 \mathrm{~g} \mathrm{l}^{-1}$ maltose $+100 \mathrm{ml}^{-1}$ coconut milk and $0.8 \%$ agar. It was found that hygromycin upto $30 \mu \mathrm{gl}-1$ was effective for selection of transformants. Putative transformants as indicated by hygromycin test were subjected to GUS assay. GUS activities were found in rice calli after cocultivation. PCR was performed to analyse the transformants.

\section{Introduction}

Rice (Oryza sativa L.) is the World's most economically important food crop and the staple food for more than one third of the world's population mainly in the tropics (FAO, 2005). Rice consumers are increasing at the rate of 1.8 per cent every year. But the rate of growth in rice production is declining. It is estimated that rice production has to increase by 50 per cent by 2025 (Khush and Virk, 2000). The increasing demand for rice provide chances for biotechnologists to develop efficient, quick and reproducible transformation protocols to meet the demand (Mahendranath et al., 2018). One of the major constraints in rice production is the damage caused by biotic and abiotic stresses. Around 37 per cent of crops worldwide are lost due to pests and diseases, of which the damage caused by insect pests alone accounts to 13 per cent (Gatehouse et al., 1999). To meet the growing demand for rice, biotechnological intervention for genetic improvement is 
becoming increasingly important. Such interventions hinge on the development of an efficient and reproducible transformation protocols for agronomically superior and popular rice varieties grown in rice consuming countries like India (Tyagi et al., 2007).

Among the various rice types available throughout the world, Basmati rice is the most preferred. Basmati rice is characterised by superfine, long slender grain, exquisite aroma, soft texture, sweet taste, delicate curvature and extra elongation with a least breadth wise swelling on cooking. Cooked basmati rice is non sticky and has longer shelf life and is easily digestible. Basmati rice commends high premium in India as well as International market. The Basmati rice from India has increased from 470000 tonnes (1996-97) to 770764 tonnes (2003-04). Highest quantum of $1.55 \mathrm{mt}$ of basmati rice was exported in 200809 earning maximum foreign exchange to the tune of Rs.9477 crores. Basmati rice is a host for number of insect pests and diseases and it is moderately susceptible to sheath rot, insect pests such as yellow stem borer, leaf folder, brown plant hoppers and gall midge invariably affect basmati rice and cause huge yield loss (Jain and Jain, 2000).

Introgression of specific genes or traits from various genetic resources into Basmati rice through Conventional breeding based on sexual hybridization, genetic recombination and selection has been cumbersome. Basmati rice breeding is difficult due to complicated nature of quality traits and poor combining ability. Genetic engineering is alternative to overcome these problems associated with narrow genetic base and tissue culture is the pre requisite event for generation of transgenic plants. More sustained production of basmati rice is essential which in turn requires an efficient protocol for its regeneration and transformation (Mahendranath et al., 2018). Improvement in transgenic technology for rice including indicas has been remarkable in past few years (Jain and Jain, 2000).

Before targeting a particular rice cultivar to in vitro genetic manipulation, we need to have an efficient regeneration of green fertile plants from explant tissues. The indica being less responsive than japonica types.

Thus it is important to establish parameters for the transformation of popular Indica varieties (Visarada et al., 2002 and Tiyagi et al., 2007). The successful protocols published so for, culturing indica rice, are largely genotype dependent, which limits the use of such protocols.

Two, transformation protocols are generally available for rice, namely Agrobacterium mediated and biolistics. Agrobacterium mediated transformation has several advantages such as higher transformation efficiency, the ability to transfer large pieces of DNA, minimal rearrangement of transferred DNA, integration in low copy numbers, low cost, easy to produce independent transformants in a single series of experiments without complicated manipulations in tissue culture.

Hence, the present investigation was under taken to establish a highly efficient, reproducible transformation protocol for aromatic indica rice varieties to improve its resistance against insect/pest, fungal diseases, salinity and drought etc.

\section{Materials and Methods}

The present study was carried out at the Tissue Culture Laboratory, Department of Plant Breeding and Genetics, Agricultural College and Research Institute, Madurai using the rice genotypes viz., Pusa Basmati 1, Pusa Sugandh 4 and Pusa Sugandh 5.Agrobacterium tumefaciens strain pCAMBIA 1305.1 was 
used for infecting the embryogenic calli in the transformation process. This strain contains plasmid encoding GUS gene GUS ( $\beta$ glucuronidase), driven by CaMV promoter and NOS terminator. This reporter gene can be used to assess the efficiency of transformation. The nptll gene encoding neomycin phosphotransferase Il (nptll) conferring Kanamycin resistance. The hpt gene conferring hygromycin resistence driven by NOS promoter and NOS terminator and TDNA border sequences.

\section{Plant material and methods}

Three aromatic elite indica rice cultivars viz., Pusa Basmati, Pusa Sugandh 4, Pusa Sugandh 5 were used in the transformation experiments. Mature seed derived embryogenic calli and immature embryo was used as explants. Immature embryos were collected approximately 12 to15 days after panicle initiation from rice plants grown in field $(10,12,14,16 \mathrm{~d})$ and calli aged 21,42 , 63 and 84 days were also used to see the effect of explant age on transformability. Immature embryos of size 0.4-0.8 mm (small),0.8-1.2 $\mathrm{mm}$ (medium), 1.5 to $2.2 \mathrm{~mm}$ (large), more than $2.2 \mathrm{~mm}$ (extra large) were used and 3 weeks old embryogenic calli were selected and cut into approximately $2-4 \mathrm{~mm}$ diameter pieces and were kept in pre induction medium for four days prior to co cultivation.

\section{Pre culture of explant}

(i) Immature seeds of Pusa Basmati1, Pusa Sugandh 4, Pusa Sugandh 5, were collected 12 to 14 days after pollination. After the removal of glumes, seed, were surface sterilized first with 70 per cent ethanol for three minutes and 0.1 per cent $\mathrm{Hgcl} 2$ for 5 min followed by three washes with sterile distilled water. Embryos were excised aseptically under a microscope. The embryos were incubated with their scutellar region facing upwards and pre cultured for 1 and 2 days in light at $25 \pm 2^{\circ} \mathrm{C}$ on pre culture medium (MS + kinetin $1.0 \mathrm{mgl}^{-1}+$ maltose $30 \mathrm{~g} \mathrm{l}^{-1}+$ casein hydrolysate $1.0 \mathrm{~g} \mathrm{l}^{-1}$ and $\mathrm{pH}$ adjusted to 5.8 .

(ii) Mature seeds of rice genotypes were sterilized as that of immature embryo and incubated on callus induction medium (MS $+2,4 \mathrm{D} 2.0 \mathrm{mg} \mathrm{l}^{-1}+$ maltose $30 \mathrm{~g} \mathrm{l}^{-1}$, case in hydrolysate $1.0 \mathrm{~g} \mathrm{l}^{-1}$ gelled with agar $8.0 \mathrm{~g} \mathrm{l}^{-1}$ ) for six weeks at $25 \pm 2^{\circ} \mathrm{c}$ in the dark for callus development. After six weeks, only embryogenic calluses were selected and cut into 2-4 mm diameter and inoculated onto pre induction medium for 2,4,6 days in dark prior to co cultivation.

\section{Callus induction}

Mature seed derived embryogenic calli were used as explants in transformation. Manually dehusked seeds were surface sterilized with 70 per cent ethanol for 3 min followed by 0.1 per cent $\mathrm{HgCl} 2$ for 5 min and washed with sterile distilled water. Sterilized seeds were cultured on MS medium (Murashige and Skoog, 1962) supplemented with IAA $2.5 \mathrm{mg} \mathrm{l}^{-1}$ Pusa Basmati 1 Pusa Sugandh 4, Pusa Sugandh 5, with $0.5 \mathrm{mg} \mathrm{l}^{-1}$ kinetin and $1.0 \mathrm{~g} \mathrm{l}^{-1} \mathrm{C} . \mathrm{H}$ and incubated in dark at $28^{\circ} \mathrm{C}$ for $2-3$ week for callus induction. The calli were subcultured and embryogenic calli transferred to fresh medium four days prior to co cultivation.

\section{Agrobacterium growth and infection}

\section{Agrobacterium culturing period (days)}

Agrobacterium strain EHA 105 harbouring p CAMBIA 1305.1 was streaked on $\mathrm{AB}$ plate supplemented with rifampicin $\left(10 \mathrm{mg} \mathrm{l}^{-1}\right)$ and kanamycin $\left(50 \mathrm{mg} \mathrm{l}^{-1}\right)$ and grown at $28^{\circ} \mathrm{C}$ in the dark and were cultured for different days viz., 1,2,3,4 days to find optimize culturing period for the Agrobacterium to effect co cultivation. 


\section{Agrobacterium density}

Different concentrations of Agrobacterium density were used viz., $0.6,0.8,1.0$, and 1.2 O.D to find out the optimum concentrations of the Agrobacterium to effect transformation.

\section{Addition of Acetosyringone (AS)}

The vir genes are induced by phenolics such as AS, and at low AS concentration vir gene induction is augmented by certain woundinduced sugars in plant cells. The influence of AS at different steps of Agrobacteriummediated transformation of indica rice was assessed using different levels of AS and sucrose. Levels of AS used were $0,100 \mu \mathrm{M}$ and $200 \mu \mathrm{M}$.

The effect of AS and sucrose on transient transformation frequency was assessed using following treatment combinations. A- Pre induction of Agrobacterium in the presence of AS and sucrose followed by co cultivation in the absence of AS, B -Pre induction of Agrobacterium in the absence of AS and presence of sucrose followed by co cultivation in the presence of AS and sucrose, C-Pre induction of Agrobacterium in presence of both AS and sucrose followed by co cultivation both in the presence of AS and sucrose and D-Pre induction of Agrobacterium in absence of AS followed by co cultivation in the absence of AS.

\section{Infection or cocultivation method}

Three different methods were used to assess the transformation frequency.

\section{Pellet method}

Five milliliters of two days grown culture of bacteria were grown by transferring a single colony to $\mathrm{AB}$ broth supplemented with kanamycin $\left(50 \mathrm{mg}^{-1}\right)$ from overnight culture,
$0.4 \mathrm{ml}$ was transferred to $30 \mathrm{ml}$ of $\mathrm{AB}$ liquid medium containing rifampicin $\left(10 \mathrm{mg} \mathrm{l}^{-1}\right)$ and kanamycin $\left(50 \mathrm{mg} \mathrm{l}^{-1}\right)$. The culture was grown overnight and bacteria were collected by centrifugation at $3000 \mathrm{rpm}$ for $10 \mathrm{~min}$. The supernatant was removed and the pellet was re suspended in $30 \mathrm{ml}$ of MS broth or AAM medium (Appendix 2) containing $100 \mathrm{mM}$ acetosyrinagone.

The explants were immersed in the bacterial suspension for $10 \mathrm{~min}$. After 10min, calli were drained and blot dried by placing on a sterile filter paper and transferred to cocultivation medium (MS + 2,4-D $2.0 \mathrm{mg} \mathrm{l}^{-1}+$ maltose 30 $\mathrm{mg} \mathrm{l}^{-1}+$ glucose $10 \mathrm{mg} \mathrm{l}^{-1}+$ casein hydrolysate $1.0 \mathrm{~g} \mathrm{l}^{-1}+\mathrm{AS} 100 \mu \mathrm{M}+$ Agar $\left.8.0 \mathrm{~g}^{-1}\right)$.

\section{Direct spotting method}

As per the procedure detailed above, the Agrobacterium was grown and the bacterial suspension mixed with AS $100 \mu \mathrm{M}$ was pippetted out and was directly spotted onto the explants kept in cocultivation medium.

Immersion of explants in bacterial suspension

The Agrobacterium suspension along with the vir inducer AS $100 \mu \mathrm{M}$ was taken in an eppendorf tube and the explants were immersed in it for different periods.

After that the explants were drained and blot dried by placing on a sterile filter paper and transferred to cocultivation medium.

\section{Cocultivation period}

The explants infected with bacterial suspension were drained, blot dried and incubated at $25^{\circ} \mathrm{c}$ in dark for different durations viz., 1,2,3,4,5 days to study the effect of cocultivation days on the transformation ability. 


\section{Washing and killing of Agrobacterium}

After the period of cocultivation, calli were washed thoroughly and were placed on a selection medium. The washing methods used here is as follows. A -With sterile distilled water alone, B-With MS broth alone, C-With sterile distilled water containing cefotaxime $\left(100 \mathrm{mg} \mathrm{l}^{-1}\right)$ and carbenicillin $\left(250 \mathrm{mg} \mathrm{l}^{-1}\right)$ and D-Without washing directly taken to selection media (containing antibiotics).

\section{Effect of Antibiotics on explant survival and rice regeneration}

To determine the optimum dose of antibiotics during callus regeneration, cefotaxime (G1BCO-BRL) and carbenicillin were added to the regeneration medium at concentrations of $0,50,100,150,200 \mathrm{mg} \mathrm{l}^{-1}$. The effective concentration of hygromycin was also determined. The concentrations tested were 0 , $10,20,30,40,50 \mathrm{mg} \mathrm{l}^{-1}$ for hygromycin. All kinds of antibiotics were added to the regeneration medium

\section{Selection and regeneration}

Following cocultivation with Agrobacterium, antibiotic resistant calli proliferated on selection medium (solid MS medium with cefotaxime $100 \mathrm{mg} \mathrm{l}^{1}+$ (Boehringer Mannheim, GmbH, Germany) carbenicillion $250 \mathrm{mg} \mathrm{l}^{-1}+$ hygromycin $\mathrm{B}$ (Boehringer Mannheim, GmbH, Germany) $30 \mathrm{mg} \mathrm{l}^{-1}+30$ $\mathrm{mg} \mathrm{l}^{-1}$ maltose + casein hydrolysate $1.0 \mathrm{~g} \mathrm{l}^{-1}+$ Agar $8.0 \mathrm{~g} \mathrm{l}^{-1}$ ). The selection cycles employed here is $1,2,3,4$ cycles comprising two weeks per cycle. After 14 days, proliferating calli were subcultured onto a fresh selection medium, proliferating calli, survived three rounds of selection each at $15 \mathrm{~d}$ interval were transferred to regeneration medium. (MS basal medium with tryptophan $1.0 \mathrm{~g} \mathrm{l}^{-1}$, maltose 30 $\mathrm{mg} \mathrm{l}^{-1}$, BAP $2.5 \mathrm{mg} \mathrm{l}^{-1}$, NAA $0.5 \mathrm{mg} \mathrm{l}^{-}{ }^{1}$ and kinetin $1.0 \mathrm{mg} \mathrm{l}^{-1}$ ) and incubated at $25^{\circ} \mathrm{C}$ under 16hr photoperiod (Datta et al., 1992). The emerging shoot buds were transferred to half strength MS medium for rooting.

\section{Molecular analysis of transgenic plants}

PCR was performed as described by Sambrook et al., (1989). PCR analysis carried out using $100 \mathrm{ng}$ of genomic DNA (for plasmid DNA $1 \mathrm{ng}$ ) in a $25 \mu \mathrm{l}$ reaction mixture containing $2 \mu \mathrm{l}$ of total DNA, 10X PCR buffer (50mM Tris- $\mathrm{HCl} \mathrm{pH} \mathrm{8.8,} 50 \mathrm{mM} \mathrm{KCl}$ and 1.5 $\mathrm{mM} \mathrm{MgCl} 2$ ), $200 \mu \mathrm{M}$ of each dNTPs, $1 \mu \mathrm{l} 1$ of each primer (forward and reverse) and 2 units of Taq DNA polymerase. The primer sequences used for amplification of gus gene are as follows,

Forward primer: G1 (5' GGTGGGAAAG CGCGTTACAAG3')

Reverse primer: G2 (5' GTTTACGCGTT GCTTCCGCCA3')

The gus sequence in total DNA was amplified in a PTC-100 minicycler (MJ Research, USA) with following temperature conditions; preincubation period at $94^{\circ} \mathrm{C}$ for $3 \mathrm{~min}$, leading to 35 cycles of denaturation at $55^{\circ} \mathrm{C}$ for $1 \mathrm{~min}$, and synthesis at $72^{\circ} \mathrm{C}$ for $1 \mathrm{~min}$, followed by extension at $72^{\circ} \mathrm{C}$ for $5 \mathrm{~min}$. Amplified PCR product $\left(\begin{array}{lll}10 & \mu \mathrm{l} & 1\end{array}\right)$ was subjected to electrophoresis on a $1 \%$ agarose gel and visualised under UV light.

\section{Statistical analysis}

A completely randomized design with three replications per treatment for each genotype was used in this study. ANOVA was done on the basis of genotype, explant size, embryos with GUS foci per cent, regeneration percentage and mean GUS foci per embryo. In some experiment, due to predominance of zero, an ANOVA was not applicable; only means and standard errors of means (SE) were 
calculated. To compare the number of GUS expression foci per embryo and to perform an analysis of variance between treatments, mean $\log$ transformations were carried out to normalize data.

\section{Results and Discussion}

Agrobacterium- mediated genetic transformation is a powerful and important tool. An efficient and reproducible transformation protocol is required for successful genetic transformation.

\section{Recovery and analysis of transformants}

Studies have indicated that in rice, efficient transformation and subsequent regeneration using Agrobacterium-mediated methods are dependent on several factors. These include, genotype, choice of explant, size of explant, age of explant, hormonal composition of the medium used, nutritional supplements, temperature and duration of cocultivation with Agrobacterium, co cultivation method, Agrobacterium density, Agrobacterium culturing period, addition of acteosyringone, inoculation time, virulence of Agrobacterium strain, concentration and composition of the bacteriostatic agent used, duration of selection and concentration of antibiotic selection marker (Cheng et al., 2004; Saharan et al., 2004 and Tyagi et al., 2007). Response of indica rice to callus induction and regeneration media is genotype specific. Therefore it is necessary to optimize these factors for each genotype that is to be transformed.

In this study the level of transient GUS expression after cocultivation with Agrobacterium in the aromatic indica rice cultivars varied with genotype. Percent transient GUS expression and total blue foci observed in this study were comparable to earlier reports in indica rice cultivars (Saharan et al., 2004; Visarada et al., 2002). In the present study Pusa Basmati 1 exhibited maximum per cent of GUS expression and total blue foci (Table 1). Pusa Basmati 1 produced the transgenic plant with maximum frequency of 20-22 percent followed by Pusa Sugandh 4, and Pusa Sugandh 5. However such differences are largely accounted by the frequencies of hygromycin resistant calli obtained after coculture of the calli with the Agrobacterium strain. Thus from the above study it has been proved that the plant genotype played a significant role for transformation efficiency Although repeated attempts were made, no transgenic indica rice genotypes were recovered containing gus gene, from matured seed derived calli. However, green loci were found on transgenic calli of indica rice genotype in regeneration medium (Table 1). The results suggests that further optimization of in vitro plant regeneration system might be needed to obtain transgenic plants from such transformed calli (Plate 12).

\section{Effect of explants}

Attachment of the bacterium to the host plant cell is an initial step in the process of infection. Attachment can be affected by plant or tissue age, cell type, cell cycle stage and other physiological parameters. Visarada et al., (2002) reported that the immature embryos are preferred as target material for transformation and other tissue explants to a lesser extent, as they are free from hassles of long term tissue culture and associated sterility. Various tissues were screened for their responses to co cultivation with A. tumefaciens. GUS expression in the tissues immediately after infection offered a good indication of preferable tissues. Early expression of GUS was observed in tissues that included shoot apices and immature embryos, tissues that were successfully transformed in previous studies (Chan et al., 
1993; Hi ei et al., 1994). Transient GUS expression interms of frequency as well as total number of blue foci indicates intensity and uniformity of gene expression. The efficiency of transformation in immature embryo derived plant was assessed by counting the ratio of the number of explants producing transgenic plants to the number of explants inoculated.

None of the mature seed derived callus explants produced transgenic plants but the total number of blue foci was higher in Pusa Basmati 1 followed by Pusa Sugandh 4. Here, the transgenic calluses exhibited green loci on the regeneration medium with a callus transformation frequency of higher per cent in Pusa Basmati 1 followed by Pusa Sugandh 4 suggesting that further optimization of in vitro plant regeneration system might be needed to obtain transgenic plants from such transformed calluses. Only immature embryo derived plantlets exhibited the maximum transformation efficiency in Pusa Basmati 1 followed by Pusa Sugandh 4 and AS D16 (Table 2).

\section{Effect of explant age}

Callus cultures are excellent source of cells for the production of transgenic rice. (Hi ei et al., 1994, 1997, Rashid et al., 1996). The use of actively growing, embryogenic calli is one of the most important factors in efficient transformation. Such calli can be obtained from mature or immature embryos. Callus age was found to have a significant impact on transformation efficiency. In our study, 42 days old calluses performed better and exhibited number of total number of blue foci (Pusa Basmati 1).

84 days old calli performed poor in all the genotypes for the trait total number of blue foci. Hence, 42 day old calli are suitable for achieve maximum transformation efficiency.
Regarding immature embryo explant it exhibited more number of total blue foci in Pusa Basmati 1 followed by Pusa Sugandh 4 . From this it could be concluded that the immature embryo explant can also be used as the starting material for transformation next to 42 days old calli. Similar observations were made by Amin et al., (2004); Saharan et al., (2004) and Rao and Rao (2007) and found highly efficient T-DNA delivery in both three week old and four week old embryogenic calli of indica rices (Table 3 and 4).

Based on the above experiment, the genotype Pusa Basmati 1 was adjudged as the best responsive one compared to others for transformation exhibiting the 42 days old calli with the maximum percent of GUS+ calli on 42 days old calli followed by 21 days. The results are in agreement with the earlier reports of Hoque et al., and Kumar et al., (2005).

Regarding the immature embryo age, embryos collected approximately 12-15 days after panicle initiation responded better and this was in agreement with the findings of Hoque et al., (2005). In contrast, Hi ei et al., (1994) used immature embryos collected 10 days after anthesis for transformation experiments (Plate 12).

\section{Effect of explant size}

The embryo size had a marked effect on DNA delivery and regeneration. The ability of immature embryos to survive the rigors of Agrobacterium cocultivation increased with increasing size. The regeneration capacity of immature embryos decreased as the size of embryo increases. The survival rate of the explants increased as the embryo size increases. Embryos with the GUS foci percent increases with the increase in embryo size and this holds good for the mean GUS foci per embryo as well. Our results are in accordance 
with the earlier report of $\mathrm{Wu}$ et al., (2003) in wheat transformation. From the above experiment it was found that the genotype Pusa Basmati 1 with the embryo size (1.5$2.2 \mathrm{~mm}$ ) had the maximum percent of embryos with GUS foci followed by Pusa Sugandh 4 and Pusa Sugandh 5. The smaller embryos exhibited the lower percent of embryos GUS foci in almost all the genotypes studied (Table $5)$.

A study was made to assess the effect of embryo size on regeneration and stable transformation efficiency in the rice variety Pusa Basmati 1 since it expressed higher percent of embryo with GUS foci and mean GUS foci per embryo compared to others, here also the frequency of regeneration decreased as the embryo size increases. Here, none of the sizes produced the transformed shoots except for the size large $(1.5-2.2 \mathrm{~mm})$. A total of 12 transformed plants could he obtained from the larger size class of immature embryos of Pusa Basmati 1. Wu et al., (2003) obtained the similar results in wheat variety Florida (Table $6)$.

Regarding the callus cultures, six weeks old embryogenic calluses were cut into approximately 2-4 $\mathrm{mm}$ diameter pieces subcultured onto pre induction medium for four days in dark $\left(25 \pm 1^{\circ} \mathrm{C}\right)$ before Agrobacterium inoculation were found to the optimum for getting maximum transient GUS expression and total number of blue foci in aromatic indica rice genotypes. In our study the calluses pre cultured for four days had a maximum survival percent (100 per cent). The parameters embryos with GUS foci percent and the per cent regeneration frequency was decreased as the pre culture days increases. Kumar et al., (2005) and Hoque et al., (2005) did the same line of work and reported the use of 2-4 $\mathrm{mm}$ diameter embryogenic calli precultured for four days before Agrobacterium inoculation for indica rice transformation. In contrast Hi ei et al., (1994) used 1-2 mm diameter calli for transformation experiments for calli derived from scuttella, and $1 \mathrm{~mm}$ calli for calli derived from shoot apices, roots, calli derived from roots and immature embryo.

\section{Effect of preculture, inoculation time and length of cocultivation days}

The duration of explant preculture, Agrobacterium inoculation and cocultivation periods were all found to affect explant survival, transient GUS expression and response in tissue culture. The effects of particular parameters on survival, TDNA delivery and regeneration did not always follow the same trend. For example, the ability of the immature embryos to survive the rigors of Agrobacterium cocultivation increased with the increasing explant size, longer preculture times and shorter inoculation times, whereas the T-DNA delivery markedly increased with the shorter preculture times, longer inoculation times. The regeneration capacity of the immature embryos generally followed the same trend as survival ability, except for embryo size where it was the opposite. These data emphasise the limitations of transient expression in non-regenerable tissue. It is clear that conditions favouring T-DNA delivery are not necessary the same as those favouring the recovery of stable transformation events (Table 7).

In our study, a pre culture period of one day (Immature embryo) and four days (callus) were found to be optimum in obtaining maximum percent embryos with GUS foci. Pre culture for a definite period helped the plants switch to an active phase of the growth and co cultivation at this stage was found to the more efficient. However use of mature seed callus explants in co cultivation without pre culturing led to commencement of tissue browning with eventual reduction in 
regeneration. The effects of increasing pre culture time using immature embryo on survival and GUS expression that observed here are contradictory to the observations of Cheng et al., (1997) and Wu et al., (2003). Weir et al., (2001) in Wheat found that a minimum of three days of pre culture was required to obtain transient and stable expression in immature embryos (Plate 9).

Hoque et al., (2005) and A1- Forkan et al., (2004) pre cultured the immature embryos for four days in dark and pre cultured the mature embryo derived calluses for a minimum of four days in dark $(27 \pm 10 \mathrm{oc})$ before Agrobacterium inoculation to get maximum transformability. In contrast, Wu et al., (2003) reported that the shorter pre culture times (0.51 hour) resulted in higher transient GUS expression.

Inoculation time/ infection period with Agrobacterium may also found to have a significant role in transient GUS expression and regeneration frequency. In this study, an inoculation time of ten minutes was found to be optimum in obtaining the higher transient expression and maximum frequency of regeneration. The longer the inoculation time, the higher the expression of GUS gene, and lower the regeneration frequency percent. In this study after 10 minutes of inoculation time the regeneration frequency decreases, but the GUS expression increases and this indicates the uniformity of GUS gene expression. Here also, a moderate and evenly distributed GUS expression is preferred than the intense one as it may cause more cell damage and mortality. Similar study was made by Hoque et al., (2005) and Tyagi et al., (2007), they reported that the immersion of explants for 10-15 minutes in bacterial suspension in five $\mathrm{cm}$ petridishes were found to optimum in getting maximum transformatiom frequency. In contrast Amin et al., (2004); Saharan et al., (2004) and Ramana Rao and Narashimha Rao
(2007) inoculated the explants by immersing them in bacterial suspension for a period of upto 30 minutes for transforming the indica rice lines.

Other important factors for co cultivation and vir gene induction are acidic $\mathrm{pH}$, incubation temperature of $28^{\circ} \mathrm{C}$ or less and high osmotic pressure. Solid medium is better for co cultivation than liquid medium $\mathrm{Hi}$ ei et al., (1997). In our study three days of co cultivation was found to be optimum in getting maximum percent of embryos with GUS foci in the variety Pusa Basmati 1 . When the duration of co cultivation increases, rate of survival of the explant, the percent of embryos with GUS foci and percent regeneration frequency decreases (Table 7). This was in agreement with the findings in Wheat. Increased duration of co cultivation may be destructive to the explant tissues. Wu et al., (2003)

\section{Effect of Agrobacterium culturing days and Agrobacterium density}

Co cultivation of explants with A.tumefaciens has made possible with the use of some explants (Opabode, 2006). Hi ei et al., (1997) reported that the transformation of rice was possible when the Agrobacterium density was between $1.0 \times 10^{6}$ and $1.0 \times 10^{10}$ colony forming units $\mathrm{ml}^{-1}$ and the optimal concentration was approximately $1.0 \times 10^{10} \mathrm{cfu} \mathrm{ml}^{-1}$ (Hi ei et al., 1994). A.tumefaciens density could increase transient GUS expression, but was not correlated with higher stable transformation frequency (Cheng et al., 1997). With higher or lower A.tumefaciens density, both transient and stable transformation decreased. A.tumefaciens density higher than $1 \times 10^{10} \mathrm{cfu}$ usually damaged the plant cells, and resulted in lower cell recovery. Nevertheless, optimum density of A.tumefaciens is necessary for recalcitrant explants or species, and here the transformation frequency can be improved by 
a short inoculation time, gently rinsing the explants after inoculation with fresh inoculation medium or addition of bactericide agent in the coculture medium (Zhang et al., 2003 and Opabode. 2006).

In this study two days of culturing of Agrobacterium was found to be optimum for reaching the required optical density of 1.0 at OD600 $\mathrm{nm}$. As the culturing days increases, the explant survival decreases. 1-2 GUS foci per explant was observed for two, three and four days of culturing and it produced a GUS response of 11.6per cent for two days and as the days increases, the percent of explants showing GUS response decreases. The Agrobacterium density of $1.0 \mathrm{OD}$ at $600 \mathrm{~nm}$ was found to be optimum in exhibiting GUS foci per explant followed by $0.8 \mathrm{OD}$. Very high (1.2 OD) and very low (0.6OD) did not produce any GUS expression. Here also as the density increases the percent survival of explant decreases (Table 8). Similar observations were made by Amin et al., (2004); Saharan et al., (2004) and Rao and Rao (2007). Who found highly efficient TDNA delivery in both three week old and four week old embryogenic calli of indica rices. In contrast Yara et al., (2001) used 3 days old culture and A1-Forkan et al., (2004) used on day old culture (1-1.5OD) for rice transformation with calli as explants

\section{Effect of acetosyringone using seed explant}

The bacterium is presumably attracted to a wounded plant in response to signal molecules released by the plant cells to which it then becomes attached (Bylebier et al., 1987). Wounded cells exude phenolic compounds, such as 4-acety1 -2,6-di methoxy phenol (acetosyringone) which activate vir genes on Ti plasmids. Rice cells might be capable of producing a certain level of signal molecules, since Raineri et al., (1990) did not add phenolic compounds in their successful attempt to obtain transgenic calli. Hi ei et al., (1994) demonstrated that acetosyringone at $100 \mu \mathrm{M}$ is a key to successful transformation of rice. The level of transient expression of GUS after co cultivation was extremely low when acetosyringone was omitted. Chan et al., (1993) used potato suspension culture cells for Agrobacterium-mediated transformation in rice. The addition of acetosyringone is essential for successful and higher frequency transformation but the concentration of acetosyringone in co cultivation medium may vary between different cultivars of rice Hi ei $e t$ al., (1997) and Malabika Roy et al., (2000).

During co cultivation, the presence of acetosyringone was required for transformation to take place. To find out the optimum conditions for co cultivation different concentration of acetosyringone was tested using two levels of acetosyringone concentration (100and $200 \mu \mathrm{M})$. For optimising the concentration of acetosyringone, the mean percent of calluses showing GUS expression obtained following each variation in co cultivation was taken as the transformation frequency. On analysing the concentration of acetosyringone it was seen that best response was observed in Pusa Basmati 1 exhibiting better performance followed by Pusa Sugandh 4 and $100 \mu \mathrm{m}$ was found to be the optimum concentration giving maximum GUS activity in the aromatic rice genotypes assessed (Table 9). This observation is similar from earlier reports in the transformation of two different Bangladeshi indica rice cultivars (Al Forkan et al., 2004 and Tyagi et al., 2007) where they reported that $100 \mu \mathrm{m}$ acetosyringone in the co cultivation medium gave maximum GUS activity. In contrast Hoque et al., (2005) used $200 \mu \mathrm{M}$ acetosyringone in the co cultivation medium to get maximum GUS activity. In the absence of acetosyringone, no transformation occurred, as it was reported by Azhakanandam et al., (2000) and Hoque et al., (2005). 
Plate 12. Agrobacterium - mediated transformation of Pusa Basmati 1 using mature seed derived calli

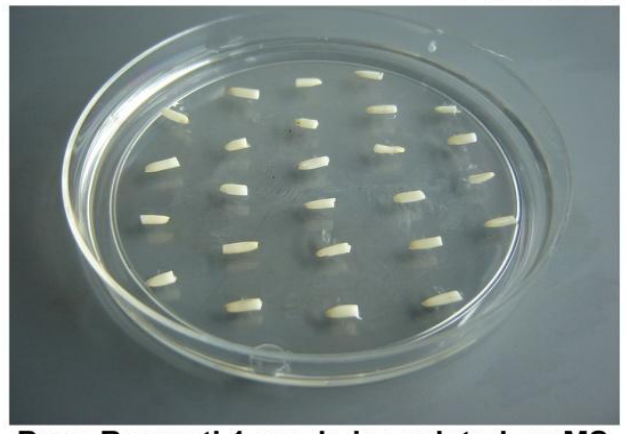

Pusa Basmati 1 seeds inoculated on MS medium containing IAA ( $2.5 \mathrm{mg} /$ litre)

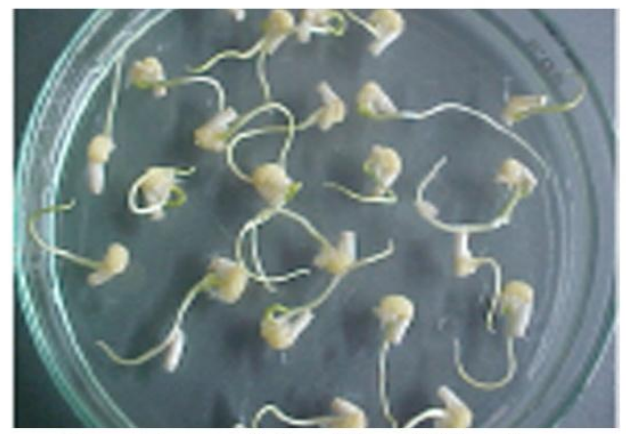

Pusa Basmati 1 calli on MS callus induction medium after one week

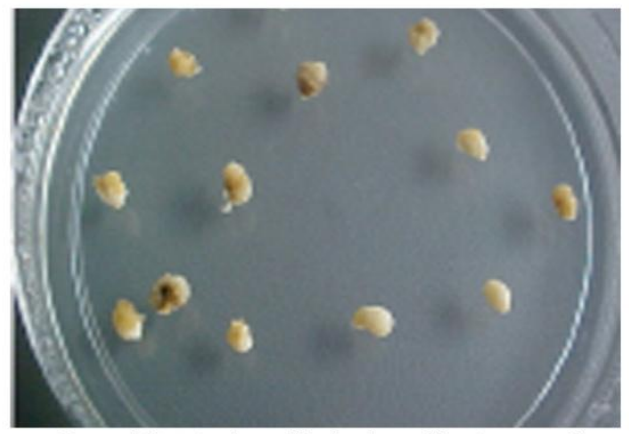

Cocultivated calli during first round of selection on hygromycin (30mg / litre)

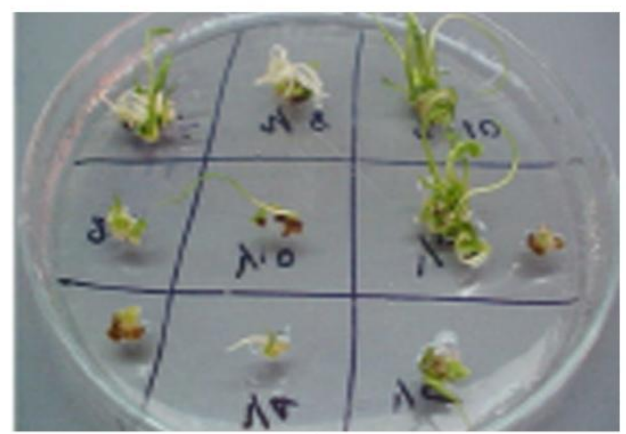

Emergence of plantlets on regeneration medium

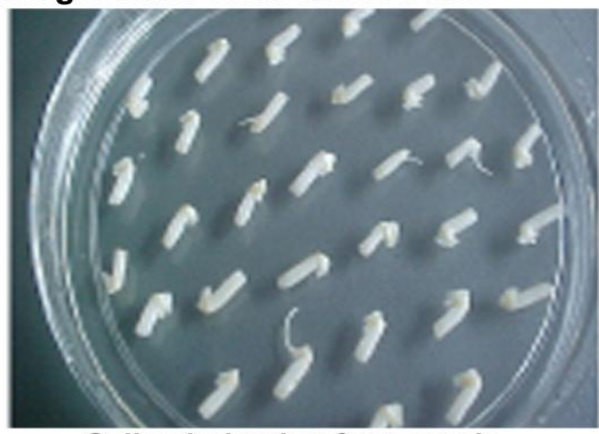

Callus induction from seeds

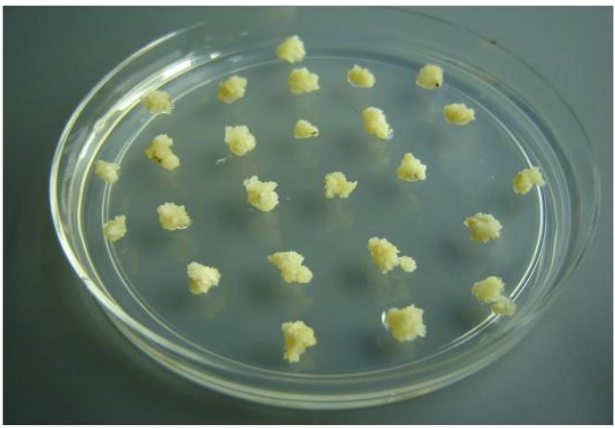

Pusa Basmati 1 calli on MS callus induction medium for proliferation

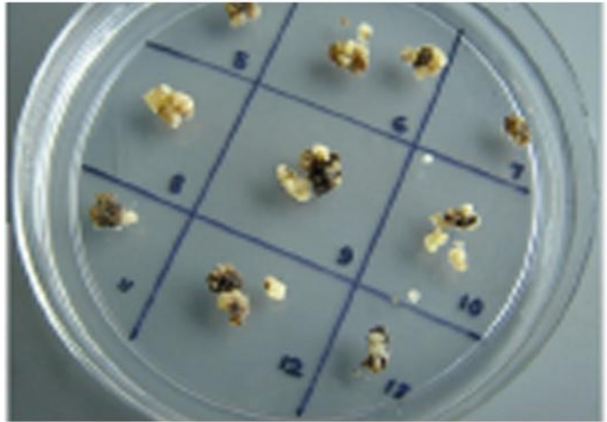

Cocultivated calli during third round of selection on hygromycin ( $30 \mathrm{mg} /$ litre)

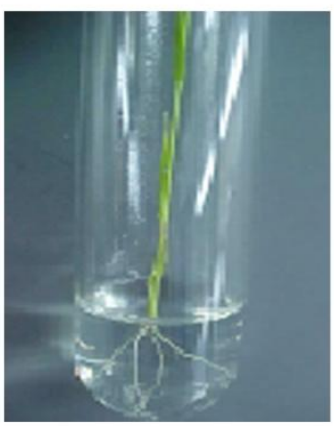

Plantlets on rooting medium 
Plate 9

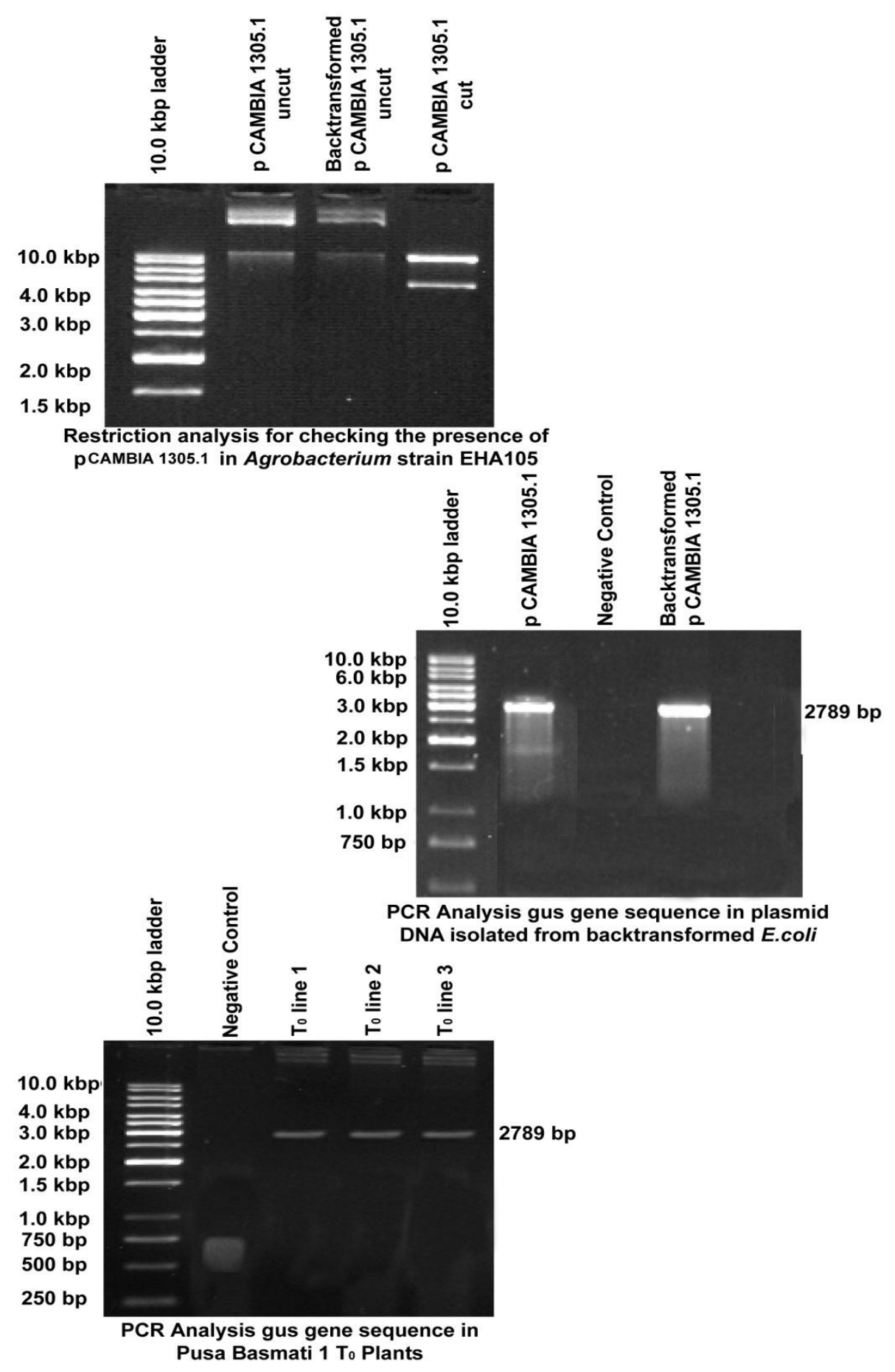


Plate 16. Transient and stable GUS expression

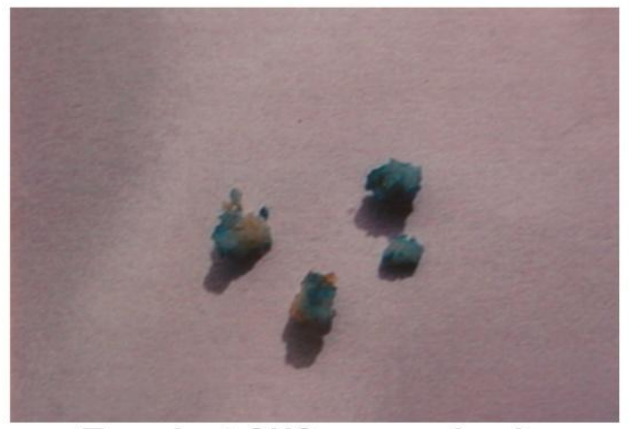

Transient GUS expression in Pusa Basmati 1

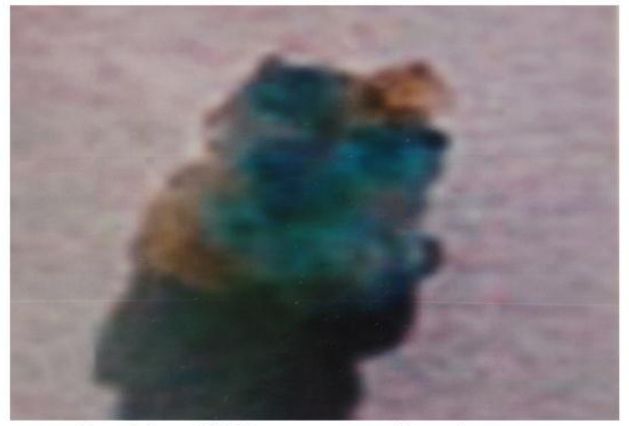

Stable GUS expression in Pusa Basmati 1

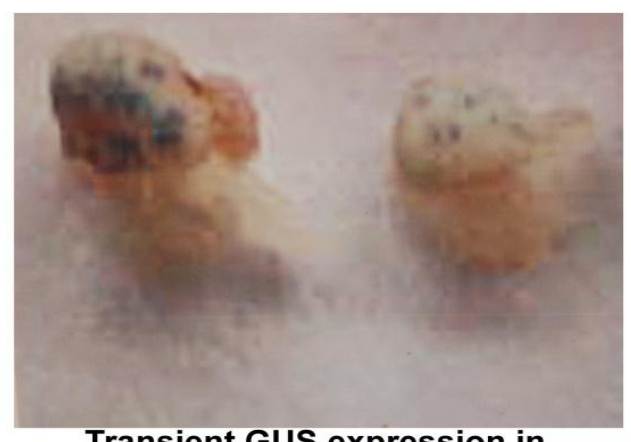

Transient GUS expression in immature embryo of Pusa Basmati 1

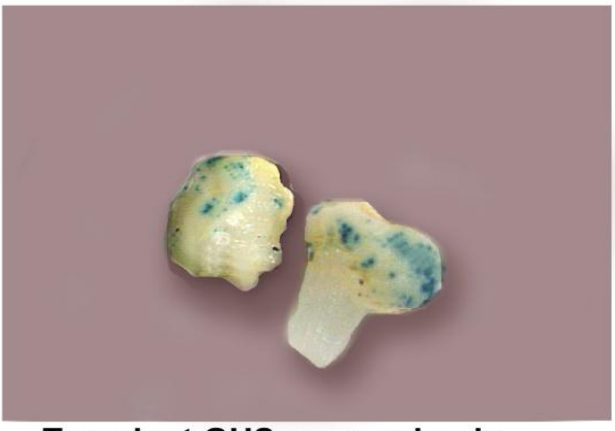

Transient GUS expression in Pusa Sugandh 4

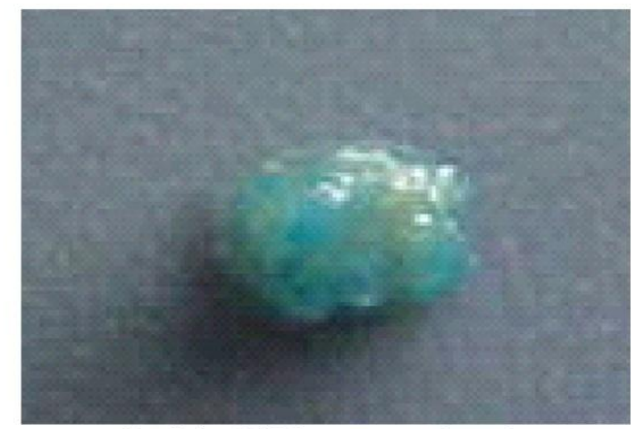

Stable GUS expression in Pusa Sugandh 4

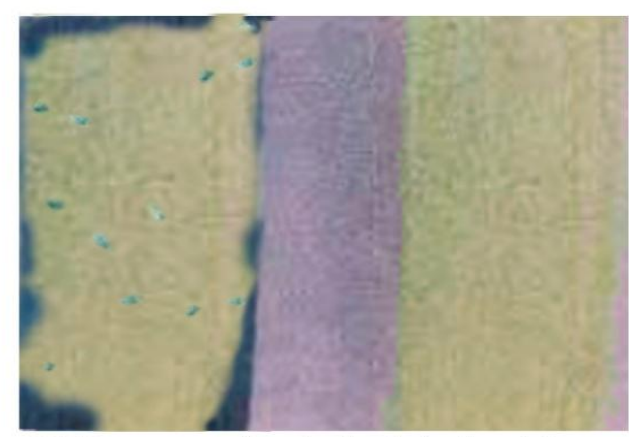

GUS expression in leaf derived from immature embryo explant 
Plate.15 Agrobacterium transformation of Pusa Basmati 1 using immature embryos

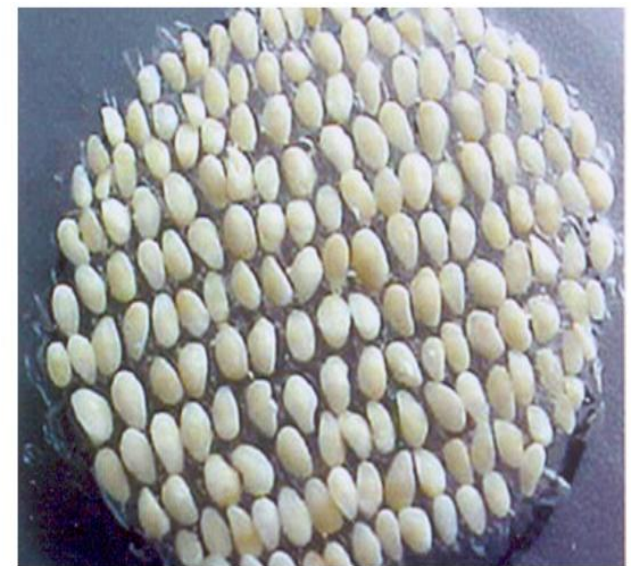

Isolated immature embryos

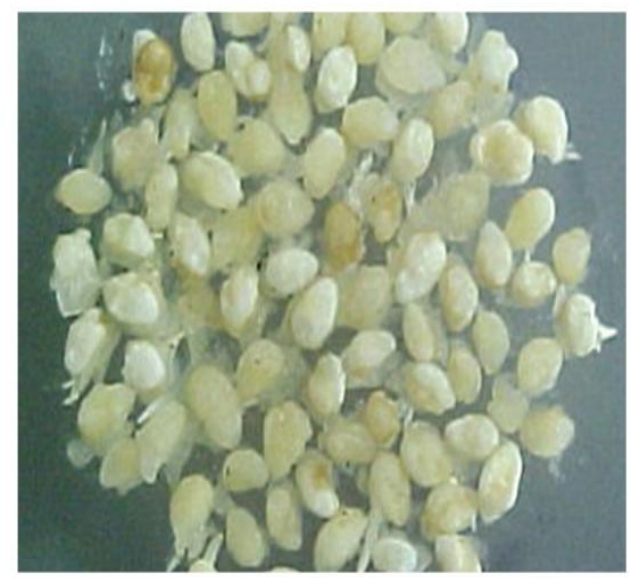

Immature embryos precultured for one day

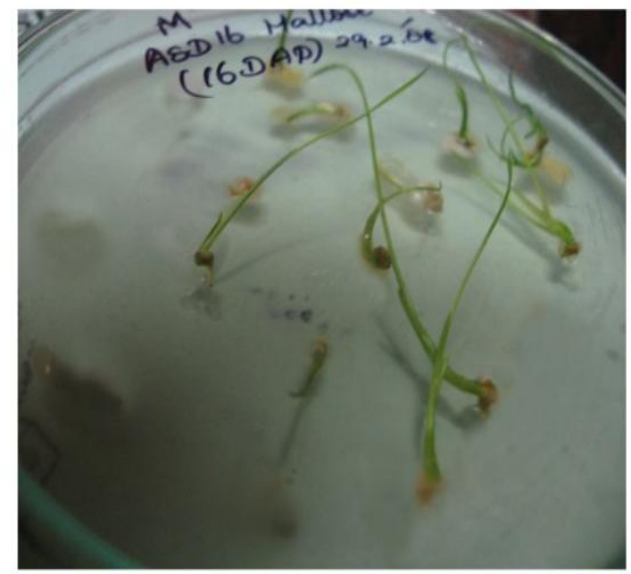

Emergence of plantlets on regeneration medium

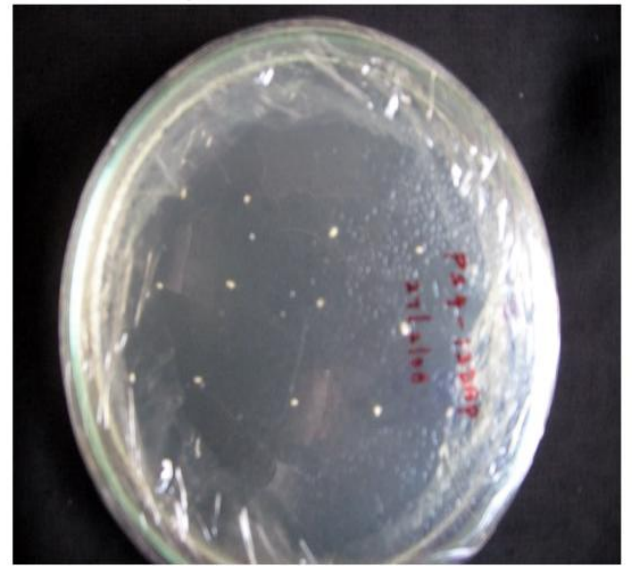

Immature embryos inoculated

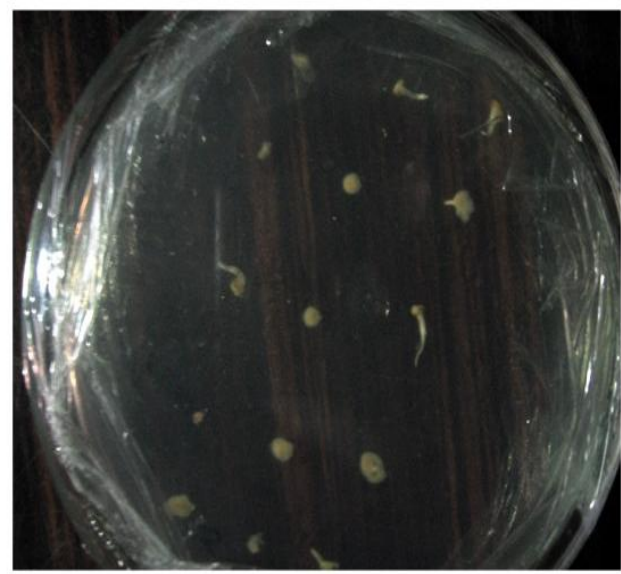

Immature embryos after cocultivation

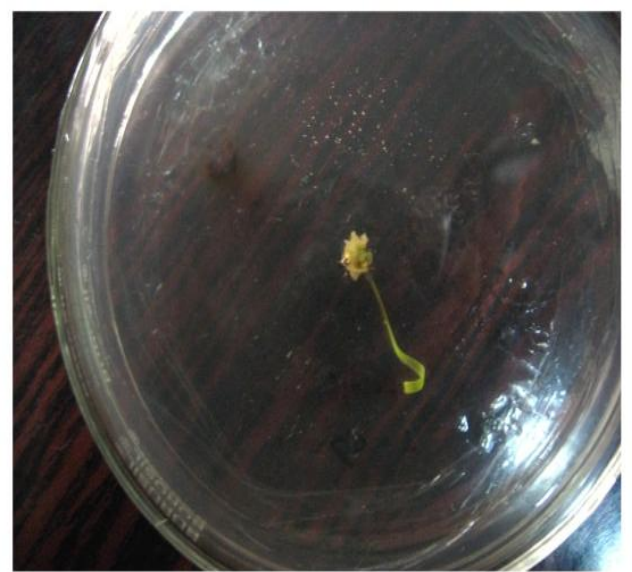

Emergence of plantlet from immature embryo 
Table.1 Efficiency of rice transformation using plasmid $\mathrm{p}^{\text {CAMBIA } 1305.1}$

\begin{tabular}{|c|c|c|c|c|c|c|}
\hline \multirow[t]{2}{*}{ Rice genotype } & \multirow[t]{2}{*}{ Explant } & \multirow[t]{2}{*}{ Expt. No } & \multicolumn{4}{|c|}{ Embryogenic calluses tested } \\
\hline & & & $\begin{array}{c}\text { No. } \\
\text { Inoculate } \\
\text { d (x) }\end{array}$ & $\begin{array}{l}\text { No. producing } \\
\text { hygromycin } \\
\text { resistant } \\
\text { calluses }\end{array}$ & $\begin{array}{c}\text { No. } \\
\text { producing } \\
\text { transgenic } \\
\text { plants (Y) }\end{array}$ & $\begin{array}{c}\text { Transformatio } \\
\text { n frequency } \\
\text { (Y / X) \% }\end{array}$ \\
\hline Pusa Basmati 1 & $\begin{array}{l}\text { Matured seed } \\
\text { derived calluses }\end{array}$ & $\begin{array}{l}1 \\
2\end{array}$ & $\begin{array}{l}50 \\
50\end{array}$ & $\begin{array}{l}8 \\
6\end{array}$ & $\begin{array}{l}8.0^{*} \\
6.0^{*}\end{array}$ & $\begin{array}{l}16.0^{\mathrm{a}} \\
12.0^{\mathrm{a}}\end{array}$ \\
\hline & $\begin{array}{l}\text { Immature } \\
\text { embryo }\end{array}$ & $\begin{array}{l}1 \\
2\end{array}$ & $\begin{array}{l}50 \\
50\end{array}$ & $\begin{array}{l}15 \\
14\end{array}$ & $\begin{array}{l}10.0 \\
11.0\end{array}$ & $\begin{array}{l}20.0 \\
22.0\end{array}$ \\
\hline Pusa Sugandh 4 & $\begin{array}{l}\text { Matured seed } \\
\text { derived calluses }\end{array}$ & $\begin{array}{l}1 \\
2\end{array}$ & $\begin{array}{l}50 \\
50\end{array}$ & $\begin{array}{l}4 \\
2\end{array}$ & $\begin{array}{l}4.0^{*} \\
2.0^{*}\end{array}$ & $\begin{array}{l}8.0^{\mathrm{a}} \\
4.0^{\mathrm{a}}\end{array}$ \\
\hline Pusa Sugandh 5 & 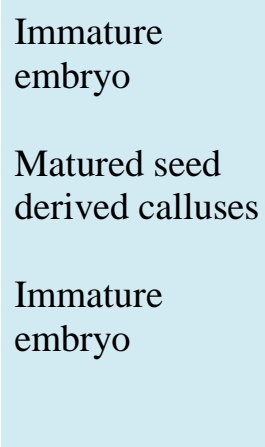 & $\begin{array}{l}1 \\
2 \\
1 \\
2\end{array}$ & $\begin{array}{l}50 \\
50 \\
\\
50 \\
50\end{array}$ & $\begin{array}{l}6 \\
6 \\
4 \\
3\end{array}$ & $\begin{array}{l}5.0 * \\
4.0 * \\
3.0 \\
0.0\end{array}$ & $\begin{array}{c}10.0 \\
8.0 \\
6.0^{\mathrm{a}} \\
-\end{array}$ \\
\hline
\end{tabular}

* Produced some green loci on the transgenic calluses a - callus transformation frequency.

Table.2 Transformation of indica rice genotypes by Agrobacterium strain EHA 105 p CAMBIA ${ }^{1305.1}$ using immature embryo explants

\begin{tabular}{|c|c|c|c|c|c|}
\hline Rice genotype & $\begin{array}{c}\text { Experiment } \\
\text { No. }\end{array}$ & $\begin{array}{c}\text { No. of } \\
\text { embryo } \\
\text { inoculated }\end{array}$ & $\begin{array}{c}\text { No. Producing } \\
\text { hygromycin } \\
\text { resistant plants }\end{array}$ & $\begin{array}{c}\text { No. producing } \\
\text { hygromycin } \\
\text { and GUS } \\
\text { plants }\end{array}$ & $\begin{array}{c}\text { Tranformation } \\
\text { Efficiency }(\%)\end{array}$ \\
\hline Pusa Basmati 1 & 1 & 50 & 10 & 10 & 20.0 \\
& 2 & 50 & 11 & 11 & 22.0 \\
Pusa Sugandh 4 & 3 & 50 & 10 & 10 & 20.0 \\
& 1 & 50 & 5 & 4 & 8.0 \\
& 2 & 50 & 4 & 4 & 8.0 \\
Pusa Sugandh 5 & 3 & 50 & 4 & 3 & 6.0 \\
& 1 & 50 & 3 & 2 & 4.0 \\
\end{tabular}


Table.3 Total number of blue foci in different explants sources transformed with $\mathrm{p}^{\text {CAMBIA } 1305.1}$ using Agrobacterium - mediated method in rice genotypes (Mean $\pm \mathrm{SE}$ )

\begin{tabular}{l|l|l|l}
\hline Explant source seed callus / Immature embryo & \multicolumn{1}{|c|}{ Pusa Basmati 1 } & Pusa Sugandlh 4 & Pusa Sugandlh 5 \\
\hline $\mathbf{2 1}$ days & $116.6 \pm 13.2$ & $113 \pm 4.5$ & $100.8 \pm 1.0$ \\
$\mathbf{4 2}$ days & $160 \pm 13.7$ & $135.2 \pm 4.9$ & $129.4 \pm 3.9$ \\
$\mathbf{6 3}$ days & $91.2 \pm 1.3$ & $88.2 \pm 3.4$ & $79.4 \pm 2.8$ \\
$\mathbf{8 4}$ days & $45.4 \pm 4.1$ & $35.2 \pm 2.0$ & $35.8 \pm 3.8$ \\
Immature embryo & $135.2 \pm 4.8$ & $127 \pm 3.9$ & $116.6 \pm 5.9$
\end{tabular}

Table.4 Effect of callus age on GUS activity of rice cultivar Pusa Basmati 1 after transformation with $\mathrm{p}$ CAMBIA 1305.1 using $100 \mu \mathrm{M}$ AS in the co cultivation medium

\begin{tabular}{|c|c|c|c|c|}
\hline \multirow[t]{2}{*}{ S. No } & \multirow[t]{2}{*}{ Age of Callus (days) } & \multicolumn{3}{|c|}{ Percentage of Calluses GUS $\pm *$} \\
\hline & & Experiment I & Experiment II & Mean \pm SE \\
\hline 1. & 21 & 29.0 & 35.0 & $32.0 \pm 4.0$ \\
\hline 2. & 42 & 44.0 & 36.0 & $40.0 \pm 4.0$ \\
\hline 3. & 63 & 23.0 & 17.0 & $20.0 \pm 2.0$ \\
\hline 4. & 84 & 14.0 & 8.0 & \pm 2.0 \\
\hline
\end{tabular}

* Data were taken 3 days after Agrobacterium inoculation and means are from 50 calluses per treatment.

Table.5 Effect of embryo size on Survival and DNA delivery (as indicated by transect GUS expression) in five rice genotypes

\begin{tabular}{|c|c|c|c|c|c|c|}
\hline $\begin{array}{c}\text { Rice } \\
\text { genotype }\end{array}$ & $\begin{array}{c}\text { Size of } \\
\text { embryo }^{\text {a }}\end{array}$ & $\begin{array}{c}\text { Number of embryos } \\
\text { tested }^{\mathrm{b}}\end{array}$ & $\begin{array}{c}\text { Survival rate } \\
\%\end{array}$ & $\begin{array}{c}\text { Embryos with GUS } \\
\text { foci }(\%)\end{array}$ & $\begin{array}{c}\text { Mean GUS foci / } \\
\text { embryo }\end{array}$ & $\begin{array}{c}\text { Mean log GUS foci / } \\
\text { embryo }^{c}\end{array}$ \\
\hline $\begin{array}{l}\text { Pusa Basmati } \\
1\end{array}$ & $\begin{array}{c}\mathrm{S} \\
\mathrm{M} \\
\mathrm{L} \\
\mathrm{XL}\end{array}$ & $\begin{array}{l}50 \\
50 \\
50 \\
50\end{array}$ & $\begin{array}{c}65.60 \\
73.40 \\
100.00 \\
92.20\end{array}$ & $\begin{array}{c}78.60 \\
90.50 \\
98.0 \\
94.10\end{array}$ & $\begin{array}{l}14.50 \\
22.50 \\
58.80 \\
28.30\end{array}$ & $\begin{array}{l}1.160 \\
1.351 \\
1.769 \\
1.451\end{array}$ \\
\hline $\begin{array}{l}\text { Pusa } \\
\text { Sugandh } 4\end{array}$ & $\begin{array}{c}\mathrm{S} \\
\mathrm{M} \\
\mathrm{L} \\
\mathrm{XL}\end{array}$ & $\begin{array}{l}50 \\
50 \\
50 \\
50\end{array}$ & $\begin{array}{c}64.30 \\
75.60 \\
100.00 \\
97.30\end{array}$ & $\begin{array}{l}81.5 \\
88.3 \\
95.5 \\
93.5\end{array}$ & $\begin{array}{c}12.0 \\
15.10 \\
52.20 \\
31.10\end{array}$ & $\begin{array}{l}1.078 \\
1.178 \\
1.717 \\
1.492\end{array}$ \\
\hline $\begin{array}{l}\text { Pusa } \\
\text { Sugandh } 5\end{array}$ & $\begin{array}{c}\text { S } \\
\text { M } \\
\mathrm{L} \\
\mathrm{XL}\end{array}$ & $\begin{array}{l}50 \\
50 \\
50 \\
50\end{array}$ & $\begin{array}{l}60.50 \\
70.20 \\
99.40 \\
59.30\end{array}$ & $\begin{array}{l}78.6 \\
80.6 \\
94.8 \\
91.4\end{array}$ & $\begin{array}{l}13.80 \\
19.40 \\
55.30 \\
30.20\end{array}$ & $\begin{array}{l}1.139 \\
1.287 \\
1.742 \\
1.479\end{array}$ \\
\hline & & $\begin{array}{r}\mathrm{G} \\
\mathrm{S} \\
\mathrm{GS}\end{array}$ & $\begin{array}{l}\text { SEd CD } \\
0.05 \%) \\
0.410 .83 \\
0.370 .74 \\
0.821 .65\end{array}$ & $\begin{array}{l}\text { SEd CD } 0.05 \%) \\
0.410 .83 \\
0.370 .74 \\
0.821 .65\end{array}$ & $\begin{array}{l}\text { SEd CD } 0.05 \%) \\
0.410 .83 \\
0.370 .74 \\
0.821 .65\end{array}$ & $\begin{array}{l}\text { SEd CD } 0.05 \%) \\
0.0110 .022 \\
0.0100 .020 \\
0.0220 .044\end{array}$ \\
\hline
\end{tabular}

${ }^{a}$ Freshly isolated, in fact immature embryo were grouped into four classes: s, 0.4-0.8mm M,0.8-1.5mm; L, 1.5 $2.2 \mathrm{~mm}$, XL Larger than $2.2 \mathrm{~mm}$

${ }^{\text {b }} 50$ embryos for each size class were used. These that survived Agrobacterium cocultivation were assayed for GUS activity.

${ }^{c}$ Analysis of variance was performed on log-transformed data of GUS foci per embryo. For each variety, the standard error differences (SEd) and least significant differences (5\% level) (lsd) were calculated for all pairs of size classes and the maximum calculated figure quoted. 
Table.6 Effect of embryo size on rice regeneration and stable transformation efficiency in rice variety Pusa Basmati1, after Agrobacterium cocultivation (NA - Not Applicable)

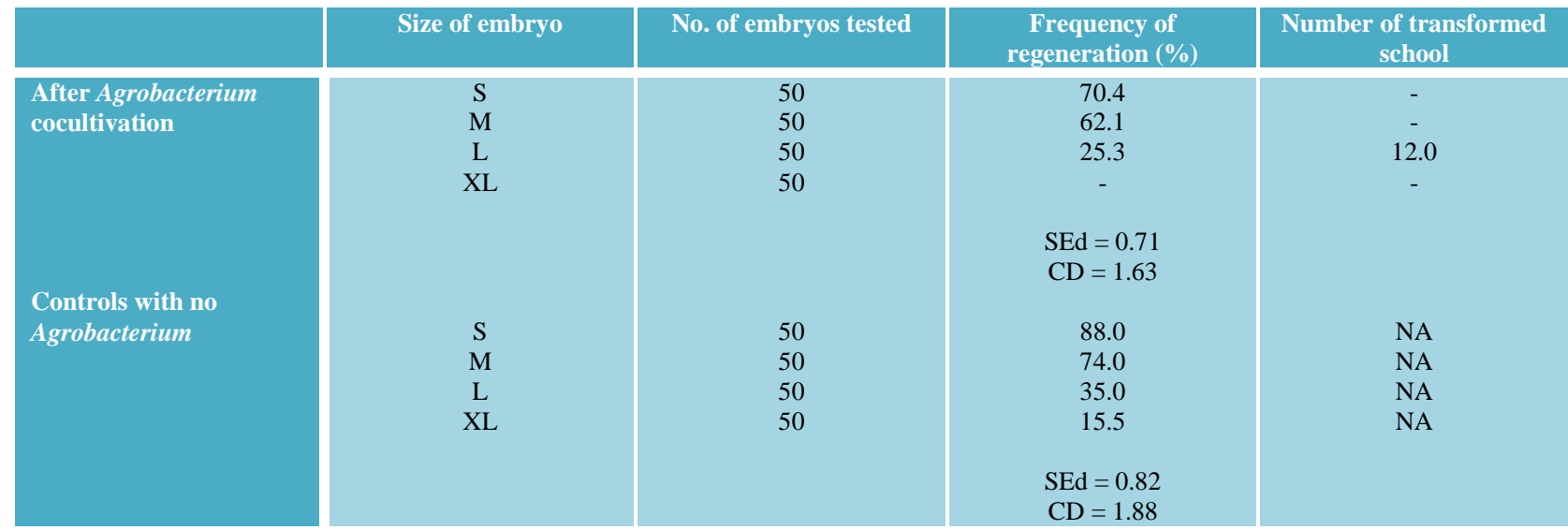

Table.7 Effect of pre culture, inoculation time, length of cocultivation days on explants survival, transgene expression and regeneration frequency (\%). Intact embryos mixed size typically between $(1.5-2.2 \mathrm{~mm})$ isolated from var. Pusa Basmati1 were cultured in the presence of Agrobacterium cells with $100 \mu \mathrm{M}$ AS

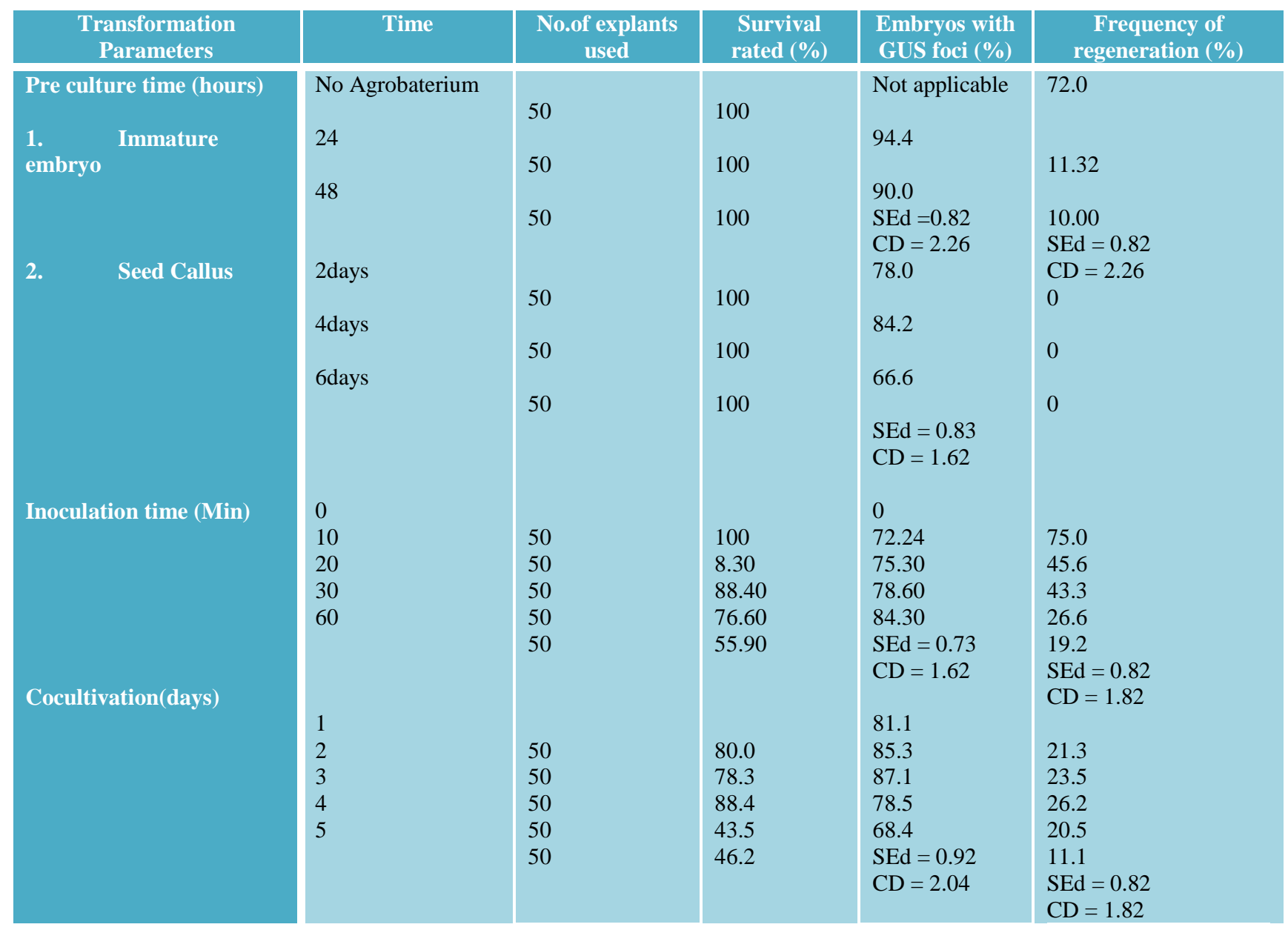


Table.8 Effect of transformation conditions on survival and GUS expression in callus and immature embryo explants transformed by Agrobacterium -method with $\mathrm{p}^{\text {CAMBIA } 1305.1}$ in the rice variety Pusa Basmati 1.

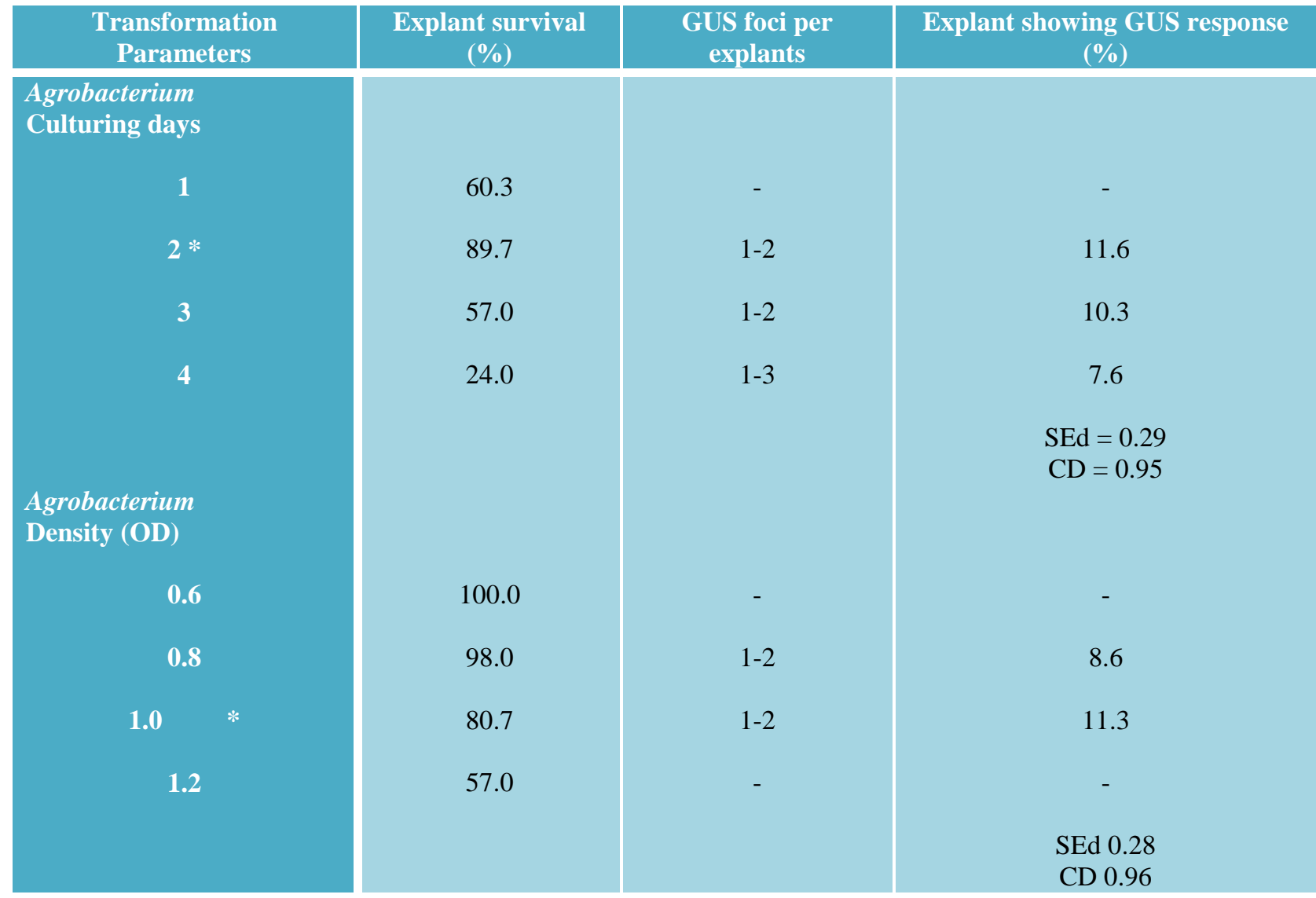

* - Chosen condition for subsequent experiments, the survival percentage and GUS expression are average of two replicates, each with 50 explants.

Table.9 Effect of genotypes and level of AS on GUS activity in calluses following Agrobacterium based transformation with $\mathrm{p}^{\text {CAMBIA } 1305.1}$

\begin{tabular}{|c|c|c|c|}
\hline \multirow[t]{2}{*}{ Rice genotype } & \multirow{2}{*}{$\begin{array}{c}\text { Concentration of AS } \\
(\mu \mathrm{M})\end{array}$} & \multicolumn{2}{|c|}{$\%$ of calluses showing GUS expression mean $\pm \mathrm{SE} *$} \\
\hline & & Small Zone & Large Zone \\
\hline Pusa Basmatis 1 & $\begin{array}{c}0 \\
100 \\
200\end{array}$ & $\begin{array}{c}0.0 \\
19.0 \pm 3.0 \\
10.0 \pm 3.0\end{array}$ & $\begin{array}{c}0.0 \\
44.0 \pm 3.0 \\
21.0 \pm 3.0\end{array}$ \\
\hline Pusa Sugandh 4 & $\begin{array}{c}0 \\
100 \\
200\end{array}$ & $\begin{array}{c}0.0 \\
15.0 \pm 2.0 \\
5.0 \pm 1.0\end{array}$ & $\begin{array}{c}0.0 \\
40.0 \pm 2.0 \\
20.0 \pm 2.0\end{array}$ \\
\hline Pusa Sugandh 5 & $\begin{array}{c}0 \\
100 \\
200\end{array}$ & $\begin{array}{c}0.0 \\
16.0 \pm 2.0 \\
5.0 \pm 1.0\end{array}$ & $\begin{array}{c}0.0 \\
21.0 \pm 2.0 \\
16.0 \pm 2.0\end{array}$ \\
\hline
\end{tabular}

* Data were taken 3 days after Agrobacterium inoculation and are the means of the two experiments with 50 calluses per treatment 
Table.10 Effect of AS DNA delivery as measured by transient GUS expression. Intact immature embryos of mixed size $(1.5-2.2 \mathrm{~mm})$ isolated from the five indica rice varieties were cultured for 3 days in the presence of Agrobacterium cells, in media either with (+) or without (-) $100 \mu \mathrm{M}$ acetosyingone

\begin{tabular}{|c|c|c|c|c|c|}
\hline $\begin{array}{c}\text { Rice } \\
\text { genotype }\end{array}$ & $\mathbf{A S}$ & $\begin{array}{l}\text { No.of embryos } \\
\text { inoculated }\end{array}$ & $\begin{array}{l}\text { Embryos with } \\
\text { GUS foci }(\%)\end{array}$ & $\begin{array}{c}\text { Mean GUS foci } \\
\text { / embryo }\end{array}$ & $\begin{array}{l}\text { Mean log GUS } \\
\text { foci / embryo }\end{array}$ \\
\hline Pusa & - & 50 & 22.80 & 12.0 & 1.08 \\
\hline Basmati 1 & + & 50 & 62.40 & 23.0 & 1.36 \\
\hline & - & 50 & 22.67 & 6.70 & 0.82 \\
\hline Pusa & + & 50 & 35.00 & 19.23 & 1.30 \\
\hline \multirow{7}{*}{$\begin{array}{l}\text { Pusa } \\
\text { Sugandh } 5\end{array}$} & - & 50 & 28.20 & 6.80 & 0.83 \\
\hline & + & 50 & 47.60 & 13.40 & 1.13 \\
\hline & & & & & \\
\hline & & & $\operatorname{SEd~CD}(0.05 \%)$ & $\operatorname{SEd~CD}(0.05 \%)$ & $\operatorname{SEd~CD}(0.05 \%)$ \\
\hline & & G & 0.611 .28 & 0.581 .22 & 0.0310 .065 \\
\hline & & S & 0.390 .81 & 0.370 .80 & 0.0200 .411 \\
\hline & & GS & 0.871 .81 & 0.821 .72 & 0.0440 .092 \\
\hline
\end{tabular}

Table.11 Effect of acetosyringone and sucrose on transient transformation efficiency in rice variety Pusa Basmati1 using seed callus

\begin{tabular}{|c|c|c|c|c|c|c|}
\hline \multirow[t]{2}{*}{ Treatment } & \multicolumn{2}{|c|}{$\begin{array}{l}\text { Pre induction } \\
\text { medium }\end{array}$} & \multicolumn{2}{|c|}{$\begin{array}{l}\text { Cocultivation } \\
\text { medium }\end{array}$} & \multicolumn{2}{|c|}{ GUS expression zones* Mean \pm SD } \\
\hline & $\mathbf{A S}$ & Sucrose & $\mathbf{A S}$ & Sucrose & Large & Small \\
\hline $\mathbf{A}$ & + & + & - & + & $21.6 \pm 0.93$ & $35.0 \pm 1.3$ \\
\hline B & - & + & + & + & $27.4 \pm 0.18$ & $35.2 \pm 1.2$ \\
\hline $\mathrm{C}$ & + & + & + & + & $35.40 \pm 1.36$ & $45.2 \pm 1.65$ \\
\hline D & - & + & - & + & $12.4 \pm 0.93$ & $46.6 \pm 1.4$ \\
\hline
\end{tabular}

* Pooled data of two experiments with fifty explants each

A preinduction of Agrobacterium in presence of AS and sucrose followed by cocultivation in the absence of AS

B pre induction of Agrobacterium in absence of AS and presence of sucrose followed by cocultivation in the presence of AS and sucrose

C pre induction of Agrobacterium in presence of both AS and sucrose followed by cocultivation both in the presence of AS and sucrose.

D pre induction Agrobacterium in the absence of AS followed by cocultivation in the absence of AS in the presence of sucrose at both stages 
Table.12 Effect of AS and sucrose on rice transformation in indica rice variety Pusa Basmati1 using immature embryo explant

\begin{tabular}{|c|c|c|c|c|c|}
\hline \multirow[t]{2}{*}{ Cocultivation } & \multicolumn{5}{|c|}{ Number of plants producing } \\
\hline & $\begin{array}{c}\text { Number of } \\
\text { embryo } \\
\text { inoculated (x) }\end{array}$ & $\begin{array}{l}\text { No. of hyg } \\
\text { producing }\end{array}$ & $\begin{array}{c}\text { No. of } \\
\text { Hyg } \\
\text { and GUS } \\
+\end{array}$ & $\begin{array}{c}\text { No. of } \mathrm{Hyg}^{\mathrm{R}} \\
\text { + GUS+ Pht } \\
\text { regenerated } \\
(\mathrm{y})\end{array}$ & $\begin{array}{c}\text { y/x Transformation } \\
\text { frequency }(\%)\end{array}$ \\
\hline With AS & 50 & 22 & 12 & 11 & 22.0 \\
\hline Without & 50 & 15 & 5 & 5 & 10.0 \\
\hline
\end{tabular}

Table.13 Effect of cocultivation method on transient GUS expression

\begin{tabular}{|c|c|c|c|}
\hline \multirow{2}{*}{ Rice genotype } & \multicolumn{2}{|c|}{$\%$ of Calluses Showing GUS expression mean \pm SE* } \\
\hline & Pellet method & $\begin{array}{c}\text { Direct spotting } \\
\text { method }\end{array}$ & $\begin{array}{c}\text { Immersion of } \\
\text { explants in bacterial } \\
\text { Suspension }\end{array}$ \\
\hline Pusa Basmati 1 & $43.0 \pm 5.0$ & $14.0 \pm 6.0$ & $44 \pm 2.0$ \\
\hline Pusa Sugandh 4 & $30.0 \pm 2.0$ & $9.0 \pm 1.0$ & $38 \pm 4.0$ \\
\hline Pusa Sugandh 5 & $17.0 \pm 3.0$ & & $21.0 \pm 3.0$ \\
\hline
\end{tabular}

* Data were taken 3 days after Agrobacterium inoculation and means are from two experiments with 50 calluses per treatment.

Table.14 Effect of cocultivation time on GUS activity in rice genotype Pusa Basmati 1 transformed with $\mathrm{p}^{\text {CAMBIA } 1305.1}$ in the presence of $100 \mu \mathrm{M}$ AS

\begin{tabular}{|c|c|c|c|}
\hline $\begin{array}{c}\text { Duration of Co } \\
\text { cultivation (days) }\end{array}$ & \multicolumn{3}{|c|}{ Percentage of Calluses GUS $\pm *$} \\
\hline 1 & Experiment I & Experiment II & Mean \pm SE \\
\hline 2 & 0.0 & 0.0 & 0.0 \\
\hline 3 & 18.0 & 14.0 & $16.0 \pm 2.0$ \\
\hline 4 & 61.0 & 45.0 & $53.0 \pm 4.0$ \\
\hline 5 & 44.0 & 36.0 & $40.0 \pm 4.0$ \\
\hline
\end{tabular}

* GUS assay was performed on 50 calluses per treatment. 
Table.15 Effect of washing and killing of Agrobacterium with antibiotics after cocultivation on transient GUS expression of rice Cultivars transformed by Agrobacterium

\begin{tabular}{|l|c|c|c|c|}
\hline Rice genotype & A & B & C & D \\
\hline Pusa Basmati 1 & - & $40.0 \pm 2.0$ & $43.0 \pm 5.0$ & $3.0 \pm 1.0$ \\
\hline Pusa Sugandh 4 & - & $32.0 \pm 2.0$ & $40.0 \pm 2.0$ & $2.0 \pm 1.0$ \\
\hline Pusa Sugandh 5 & - & $16.0 \pm 2.0$ & $17.0 \pm 3.0$ & $2.0 \pm 1.0$ \\
\hline
\end{tabular}

Date were taken 3 days after cocultivation and are the means of two experiments with 50 calluses per treatment.

A With sterile distilled water alone

B MS Broth alone

C with sterile distilled water containing cefotaxime (100 $\left.\mathrm{mg} \mathrm{l}^{-1}\right)$ and carbeniceilln $\left(250 \mathrm{mgl}^{-1}\right)$

$\mathrm{D}$ without washing directly taken to selection media containing antibiotics

Table.16 Number of blue foci exhibited by rice calli transformed by cocultivation with Agrobacterium - method after different intervals of selection

\begin{tabular}{|c|c|c|c|c|}
\hline Rice genotype & 1 day & $1^{\text {st }}$ Cycle & $2^{\text {nd }}$ Cycle & $3^{\text {rd }}$ Cycle \\
\hline Pusa Basmati 1 & $165 \pm 6.7$ & 15.0 & $4^{*}$ & $2^{*}$ \\
Pusa Sugandlh 4 & $147.6 \pm 8.3$ & 7.0 & $2 * *$ & $1^{* *}$ \\
\hline Pusa Sugandh 5 & $133.6 \pm 6.7$ & 4.0 & 3 & 2
\end{tabular}

* - Large blue sector, ** - Small blue sector

Table.17 Effect of different concentrations of cefotaxime and carbenicillin on plant regeneration from the calli of indica rices* (Mean $\pm \mathrm{SE}$ )

\begin{tabular}{|c|c|c|c|c|}
\hline \multirow{2}{*}{$\begin{array}{c}\text { Concentration of } \\
\text { cefotaxime / } \\
\text { carbenicillin }\left(\mathrm{mg}^{-1}\right) \\
\end{array}$} & \multicolumn{2}{|c|}{ Cefotaxime concentration $\left(\mathrm{mgl}^{-1}\right)$} & \multicolumn{2}{|c|}{ Carbenicillin concentration $\left(\mathrm{mgl}^{-1}\right)$} \\
\hline & $\begin{array}{l}\text { No.of Shoots / } \\
\text { Callus }\end{array}$ & $\begin{array}{c}\text { Precent } \\
\text { regeneration }\end{array}$ & No.of shoots / callus & $\begin{array}{c}\text { Percent } \\
\text { regeneration }\end{array}$ \\
\hline 0 & 6 & $60 \pm 2.0$ & 6 & $62 \pm 3.0$ \\
\hline 50 & 3.9 & $52 \pm 2.0$ & 4.2 & $50 \pm 2.0$ \\
\hline 100 & 3.5 & $50 \pm 1.0$ & 3.9 & $48 \pm 2.0$ \\
\hline 150 & 3.0 & $15 \pm 1.0$ & 3.5 & $31 \pm 1.0$ \\
\hline 200 & 1.0 & $9 \pm 1.0$ & 3.0 & $30 \pm 1.0$ \\
\hline 250 & 0.0 & $0.0 \pm 0.0$ & 2.2 & $25 \pm 1.0$ \\
\hline
\end{tabular}

* The values are average of five replicates. 
Table.18 Effect of different concentrations of hygromycin on plant regeneration from the calli of indica rices* $($ Mean $\pm \mathrm{SE})$

\begin{tabular}{|c|c|c|} 
Concentration of hygromycin $\left(\mathrm{mgl}^{-1}\right)$ & No. of shoots / callus & Percent regeneration \\
\hline 10 & $60 \pm 3.0$ & 6 \\
20 & $52 \pm 2.0$ & 3.2 \\
30 & $34 \pm 2.0$ & 1.9 \\
40 & $20 \pm 1.0$ & - \\
50 & - & -
\end{tabular}

* The values are average of five replicates.

Table.19 Transgene expression in immature embryo derived $\mathrm{T}_{0}$ plants of the indica rice cv PB1 transformed with Agrobacterium strain EHA105 P CAMBIA 1305.1

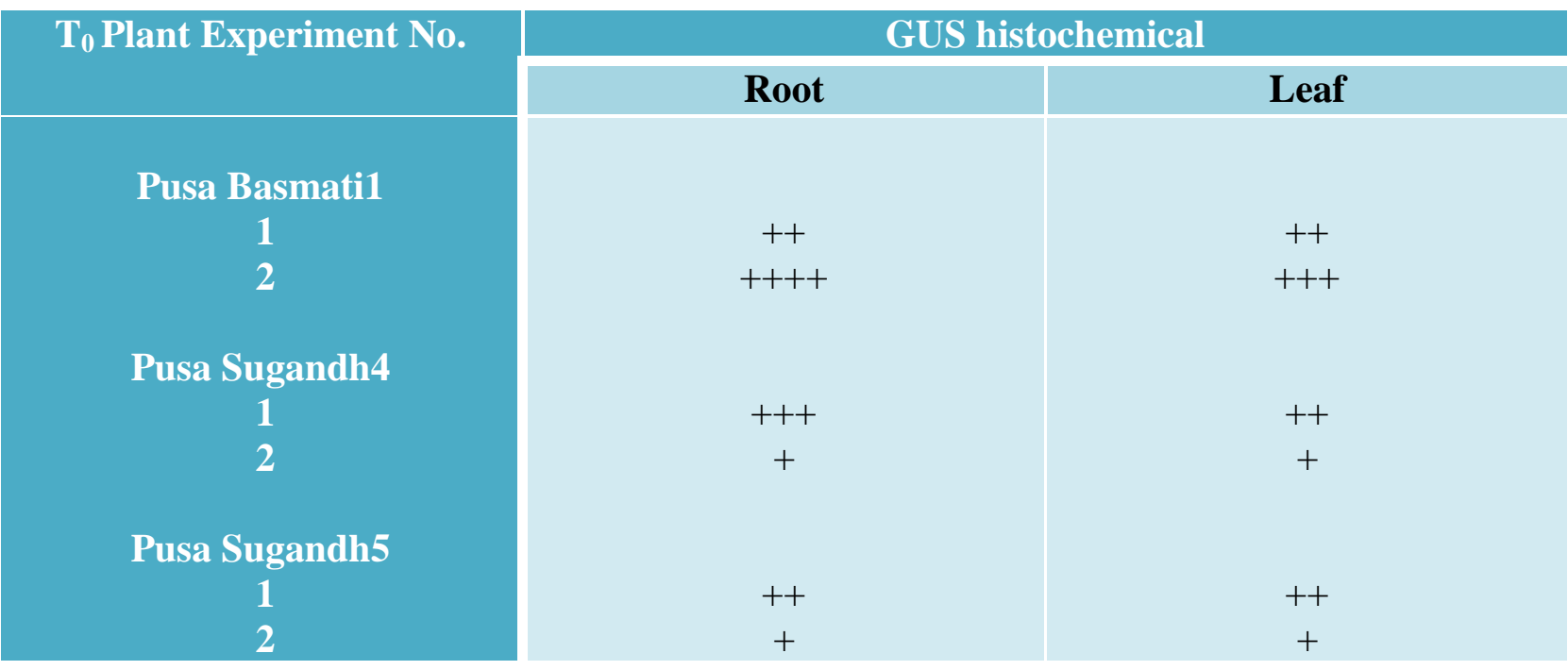

,,,$++++++++++=$ Visual estimation of intensity of GUS Staining.

Effect of acetosyringone using immature embryo explant

Phenolic inducers such as acetosyringone at specific temperatures and an acidic environment promote the expression of Agrobacterium vir genes, the products of which mediate T-DNA delivery. The results had shown that the presence of $100 \mu \mathrm{M}$ acetosyringone in the medium markedly increased the T-DNA delivery without losing the regeneration potential of the immature embryos in all the three aromatic indica rice genotypes tested and it influenced the transient GUS expression to a higher extent in all the three aromatic indica rices, as measured by embryos with GUS foci percent, mean GUS foci per embryo and mean log 
GUS foci per embryo. This supports the earlier works in a number of species showing that the addition of acetosyringone during preculture and cocultivation increases the number of transformed cells in the target tissues (Wu et al., 2003). In rice immature embryo, $100 \mu \mathrm{M}$ acetosyringone gave optimum transient gene expression, with higher concentrations being toxic and lower concentrations less effective (Amoah et al., 2001 and $\mathrm{Wu}$ et al., 2003) (Table 10).

\section{Efect of acetosyringone and sucrose using seed explant}

The frequency of the transient transformation is expressed as the ratio between the number of calli showing GUS expression and the total number of calli kept for staining. For qualitative assay, the area of GUS expression and the intensity of the blue colour at each spot were given due weightages so as to give a holistic picture of the effect of the various treatments tested. Through visual observation, distinction could be made between small spots $(<0.5 \mathrm{~mm}$ in diameter) representing one or few GUS expressing cells, and large spots ( $\geq 1 \mathrm{~mm}$ in diameter), representing a complete cell cluster expressing the GUS gene (De Clercq et al., 2002). Based on this assay, the efficacy of acetosyringone was evaluated.

Our experiment was aimed to assess the need for acetosyringone at pre induction medium or co cultivation or both stages for Agrobacterium-mediated gene transfer to rice calluses. Addition of AS for both stages induced high levels of GUS expression zones consistently in contrast to low levels of expression in the presence of AS either only at pre induction medium or only at co cultivation medium stages. Similar levels of GUS expression zones were also obtained in sucrose supplemented media devoid of AS in pre induction medium or co cultivation medium or both the results are in agreement with the reports of Ramana Rao and Narashimha Rao (2007) (Table 11).

\section{Effect of acetosyringone and sucrose using immature embryo explant}

In addition to high transient GUS expression under AS-free conditions, stable transformation was achieved with both AS and AS-free plus sucrose treatments. After four selection cycle, the proliferated shoots on selection medium showed stable GUS expression and the Gus positive plants produced normal green shoots in the regeneration medium. The results are similar to the earlier report of Ramana Rao and Narashimha Rao (2007). The variety Pusa Basmati 1 using mature seed derived calli as explants exhibited a maximum transformation frequency with or without AS. Their results provide strong evidence for the first time that acetosyringone may not be essential for the induction of vir genes of Agrobacterium during co culture for transformation of recalcitrant genotypes like indica rices (Table 12).

\section{Effect of infection time}

The T-DNA delivery is markedly increased with the longer inoculation or infection time. A period of zero minute to 60 minutes was studied to find out the optimum inoculation time of Agrobacterium with explants. Our study showed that 10 minutes time was found to be the best for infection time for the seed explants of indica rice genotypes. The longer the duration, the higher the percentage of embryos with GUS foci. This result was in agreement with the earlier report of $\mathrm{Wu}$ et al., (2003) who stated that the shorter inoculation times has the ability of immature embryos to survive with Agrobacterium during co cultivation and also reported that the T-DNA delivery increased with the longer inoculation times. 


\section{Effect of co cultivation method}

Three different methods viz., pellet method, direct spotting method and immersion of explants in bacterial suspension were used for transforming different indica rice genotypes. The basic differences between these three methods were (i) centrifuging the Agrobacterium cells and re suspending the pellets in amino acid broth or MS broth (ii) direct spotting of the Agrobacterium cell suspension over the explants (iii) immersing the explants in bacterial suspension cultures grown overnight. These three methods appeared to have significantly enhanced transformation efficiency of putative transgenic lines of Pusa Basmati 1. Immersion of explants in bacterial suspension method had the strong influence in all the genotypes studied, as it had maximum GUS expression in the calluses followed by pellet method. While the direct spotting method exhibited the poor response indicating the maximum exposure of the calli to the Agrobacterium cells causes the death of the explants (Table 13). Kumar et al., (2005) used pellet method for co cultivation of indica rices and obtained a transformation frequency of 25.8 percent in Pusa Basmati 1.

Immersion of explants in bacterial suspension got maximum GUS expression in rice as it was reported by earlier workers Hoque et al., (2005) ; Yara et al.,(2001); Saharan et al., (2004); A1-Forkan et al., (2004) and Ramana Rao and Narashimha Rao (2007). Our results demonstrated that among the three methods used, immersion of explants in bacterial suspension was found to be the best one for indica rice genotypes compared to others.

\section{Effect of co cultivation time}

To find out the optimum conditions for co cultivation, duration of co cultivation was tested. For this the percentage of calluses showing Gus expression was calculated and the means are presented in Table 14. It was found that the co cultivation for three days in the presence of $100 \mu \mathrm{M}$ acetosyringone was found to be the most suitable for optimum transformation. In our study it was observed that a maximum of 53 percent of calluses showing GUS expression for three days of co cultivation compared to others. Co cultivation for a period more than three days resulted in the calluses becoming prone to repeated Agrobacterium infection, which ultimately resulted in the loss of regeneration potential. Although calluses, which were co cultivated for more than three days showed some GUS activity, they were adversely affected by the over growth of Agrobacterium and subsequently died. Similar line of work was reported by Al Forkan et al., (2004); Saharan et al., (2004); Hoque et al., (2005) and Ramana Rao and Narashimha and Rao (2007). But Tyagi et al., (2007) reported that co cultivation for two and a half days in the presence of $100 \mu \mathrm{M}$ acetosyringone was found to be the most suitable for indica rice transformation.

\section{Effect of washing and killing of Agrobacterirum}

Calli cocultivated with Agrobacterium for three days were washed with shaking by using four different methods viz., A- sterile distilled water alone, B -MS Broth alone C-with sterile distilled water containing cefotaxime $(100 \mathrm{mg}$ $\left.\mathrm{I}^{-1}\right)$ and carbenicillin $\left(250 \mathrm{mg} \mathrm{l}^{-1}\right)$ and D Without washing directly taken to selection media containing antibiotics. This experiment was carried out to find out the best method of washing and killing of Agrobacterium to get maximum regeneration frequency. Successful transformation events in the calli infected with Agrobacterium tumefaciens EHA 105 pCAMBIA 1305.1 were followed by transient GUS assay using X-Gluc as a substrate. A good positive response for transient GUS 
assay for Pusa Basmati 1 was obtained for the method washing with sterile distilled water containing cefotaxime (100 $\left.\mathrm{mg} \mathrm{l}^{-1}\right)$ and carbenicillin $\left(250 \mathrm{mg} \mathrm{l}^{-1}\right)$ compared to other methods (Table 15).

Blue spots were visualized on the co cultivated calli, which indicated positive transient GUS expression in the cells of calli. For negative control the control calli were subjected to exactly same treatment of transient assay showed no blue colour. An average of 5.9 and $7.6 \%$ efficiency for GUS positive calli in indica varieties viz., TCS 10 and IR 72 respectively were reported by Aldemita and Hodges (1996). Hoque et al., (2005) reported the transformation frequency of $11.1 \%$ was obtained using immature embryo and stated that the production of transgenic plant was more successful using immature embryos than mature embryo derived calluses. In the present study also we could able to produce transgenic plants using immature embryo with a transformation frequency of $20-22 \%$ in the variety Pusa Basmati 1 compared to other genotypes (Plate 16).

\section{Effect of selectable marker genes and selection cycle}

Maintenance of the embryogenic status of the calli on the selection medium is important for the efficient recovery of regenerants. Inclusion of a selective agent in the regeneration and rooting media greatly favours the production of transgenic plants that stably express transgenes. Aldemita and

Hodges (1996) used a regeneration medium without hygromycin and showed less than 50 percent regenerants were GUS positive. Hi ei et al., (1994) and Komari et al., (1996) added hygromycin to their regeneration media and 85 percent of regenerants stably expressed the GUS gene. Most widely used and effective selectable marker is hygromycin phosphotransferase which confers resistance to aminoglycoside antibiotic hygromycin that allows clear discrimination between transformed and non-transformed tissues and problems with albinos or the fertility of regenerants (Dong et al., 1996 and Rashid et al., 1996).

In many successful attempts to transform rice, genes for selectable markers have been driven by the constitutively expressed $\mathrm{Ca}$ MV35S promoter. This appears to give direct strong expression of genes for the selection of transformants at high frequency. In our study also we obtained strong expression using $\mathrm{Ca}$ MV 35S promoter for the expression of $\mathrm{hph}$ gene. Considerable differences were found in transgene expression of hygromycin selected plants even between the plants of the same variety. This type of variation in gus and hph gene expression has been reported previously in rice by Kumar et al., (2005).

Continuous selection on hygromycin containing medium resulted in the appearance of proliferating apparently resistant embryogenic calli. The gene encoding GUS has been most widely used as reporter gene for the analysis of plant gene expression in plant transformation systems described by Jefferson et al., (1997). Efficient plant selection during transformation requires a substantial level of expression of the selectable marker gene (Wang et al., 1997). In the present study, calli co cultivated with EHA 105 strain containing pCAMBIA 1305.1 was allowed to grow and subjected to three cycles of selection of 15 days each in the selection medium containing $30 \mathrm{mg} \mathrm{l}^{-1}$ hygromycin, $100 \mathrm{mg} \mathrm{l}^{-1}$ cefotaxime and 250 $\mathrm{mg} \mathrm{l}^{-1}$ carbenicillin. Continuous selection (4 to 6weeks) on hygromycin medium resulted in the selective proliferation of resistant calli. In the present study, the total number of blue foci exhibited by Pusa Basmati 1 (165) was 
maximum. After two cycles of selection in Pusa Basmati 1 the blue sectors expressing the reporter gene were large, where as it was localized to small areas in Pusa Sugandh 4. Putative transgenic calli were obtained in all genotypes (Table 16). Similar results were reported by Visarada et al., (2002) using particle bombardment. With respect to immature embryo, transfer of transformed plants to fresh selection medium at every 15 days interval improved the selection efficiency. On extending the selection for three cycles stable transformed plants could be obtained with $20-22 \%$ transformation frequency in immature embryo derived plants in the variety Pusa Basmati 1 which supported the view that selection for three cycles on hygromycin at $30 \mathrm{mg} \mathrm{l}^{-1}$ helped to obtain stable transformed plants as reported by Hoque et al., (2005) used 250mg $1^{-1}$ cefotaxime for killing of Agrobacterium and $50 \mathrm{mg} \mathrm{l}^{-1}$ hygromycin B for the selection of transformed tissues. Whereas Saharan et al., (2004) produced hygromycin resistant calli with $250 \mathrm{mg} \mathrm{l}^{-1}$ carbenicillin and $50 \mathrm{mg} \mathrm{l}^{-1}$ hygromycin by employing two cycles of selection with 15 days each.

\section{Effect of antibiotics on rice regeneration}

Antibiotics such as cefotaxime, carbenicillin and timention have been used regularly in Agrobacterium transformation (Opabode.2006). It was observed that cefotaxime at $250 \mathrm{mg} \mathrm{l}^{-1}$ had a detrimental effect to maize Hi II callus, callus formation was greatly reduced when cefotaxime (50 or $250 \mathrm{mg} \mathrm{l}^{-1}$ ) was added in the callus induction medium (Ishida et al., 1996). Carbenicillin has been the antibiotic of choice in reports of Agrobacterium-mediated transformation of wheat and maize (Zhang et al., 2003). In our study we used antibiotics in order to eliminate A.tumefaciens after co cultivation. Unfortunately the concentrations required in many cases inhibit the regeneration of the plant tissue (Barette and Cassells, 1994). The capacity of carbenicillin and cefotaxime in controlling the growth of Agrobacterium on the regeneration of the calli of indica rices showed that there was strong inhibition of the regeneration potential. The reduced regeneration capacity is in agreement with the results obtained by Pipatpanukul et al., (2004) reported that $250 \mathrm{mg} \mathrm{l}^{-1}$ cefotaxime and carbenicillin played an inhibitory effect on rice regeneration. In this study cefotaxime more than $100 \mathrm{mg} \mathrm{l}^{-1}$ and carbenicillin more than $250 \mathrm{mg} \mathrm{l}^{-1}$ had the strong inhibitory effect on rice regeneration and number of shoots produced per callus. While the concentration lower than this level showed a positive effect on rice regeneration (Table 17).

\section{Effect of hygromycin on rice regeneration}

Concentrations of selective agents are needed to avoid development of undesirable number of the escapes. In this experiment, a selectable marker gene hph (encoding resistance to hygromycin) was used in the production of transgenic rice. Hygromycin is aminoglycoside antibiotics which cause harmful death to plant cells by inhibiting transcription and translation. Cheng et al., (1998) reported the presence of $50 \mathrm{mg} \mathrm{l}^{-1}$ hygromycin throughout the callusing as well as regeneration periodis necessary to avoid development of the escapes. The presence of hygromycin decreased the number of shoots and percent regeneration in all treatments. Hygromycin clearly affected regeneration capacities.

Complete inhibition of plant regeneration and no shoot regeneration from rice calli was observed at $40-50 \mathrm{mg} \mathrm{l}^{-1}$ hygromycin. Upto $30 \mathrm{mg} \mathrm{l}^{-1}$ hygromycin had a positive effect on shoot formation and regeneration (Table 18 and 19). Most of the earlier workers used 50 $\mathrm{mg}^{-1}$ hygromycin in their transformation 
experiments in rice (Amin et al., 2004 and Hoque et al., 2005).

The low efficiency in plant regeneration of rice calli co cultivated with Agrobacterium was achieved in this study. This might be related to the prolonged period of tissue culture. The calli were almost six weeks old before co cultivation and were maintained for more than four weeks on the selection medium to ensure no escape of non transformants. Wu et al., (1998) reported the loss of morphogenic capacity in the established transformed calluses and suggested that reduction of the culture period enhanced plant regeneration (Plate 15).

The result obtained in the present study gives that the optical density of the Agrobacterium, acetosyringone concentration and cocultivation time is critical parameters that influence the transformation in aromatic indica rices. The genetic transformation method developed in our study is used to developed T-DNA based activation tagging lines, which involved in develop the gain of functional mutations in recalcitrant indica rice cv Pusa Basmatil and other aromatic rice varieties. An efficient protocol for the transformation has been developed by this procedure, which can help to greately strengthen Basmati rice breeding programme involving transfer of novel genes to improve its resistance against insect pests, diseases, salinity and drought etc and resistance to yellow stem borer can easily be engineered in Basmati varieties without altering its genetic background or quality traits which has been difficult in achieving through sexual hybridization involving crosses with nonBasmati rice varieties.

\section{References}

Aldemita, R. R., and T. K. Hodges. 1996. Agrobacterium tumefaciens- mediated transformation of japonica and indica rice varieties. Plants, 199: 612-617.

Al-Forkan, M., J. B. Power, P. Anthony, K. C. Lowe and M. R. Davey. 2004. Agrobacterium mediated transformation of Bangaldeshi indica rices. Cellular and Mol. Bio. Lett., 9 (2): 287-300.

Al-Forkan, M., M. A. Rahim, T. Chowdhury, P. Akter and L. Khaleda. 2005. Development of highly in vitro callogenesis and regeneration system for some salt tolerant rice (Oryza sativa L.) cultivars of Bangaladeshi. Biotech., 4: 230-234.

Amin, M. A., M. A. Uddin and M. A. Hossain. 2004. Regeneration study of some indica rice cultivars followed by Agrobacterium - $\quad$ mediated transformation of highly regenerable cultivar, BR-8. J. Bio. Sci., 4(2): 207211.

Amoah, B. K., H. Wu, C. Sparks and H. D. Jones. 2001. Factors influencing Agrobacterium - mediated transient expression of uid A in wheat inflorescence tissue. J. Exp. Bot., 52: $1135-1142$.

Azhakanandam, K., S. Mathew, J. McCabe, Brain Power, K. C. Lowe, E. C. Cocking M. R. Davey. 2000. T-DNA transfer, integration, expression and inheritance in rice: effects of plant genotype and Agrobacterium super virulence. J. Plant Physiol., 157: 429439.

Barett, C and A. C. Cassells. 1994. An evaluation of antibiotics for the elimination of Xanthomonas campestris Cv. Pelargonii (Brown) from Pelargonium domesticum cv. Grand Slam explant in vitro. Plant Cell Tiss. Org. Cult., 36: 169-175.

Bylebier, B., F. Deboeck, H. DeGrave, M. Van Montagu and J. P. Hernalsteens. 1987. T-DNA organization in tumor cultures and transgenic plants of 
monocotyledon Asparagus officinalis. Proc. Natl. Acad. Sci., USA., 84: 53455349.

Chan, M. T., H. H. Chang, S. L. Ho, W. F. Tong and S. M. Yu. 1993. Agrobacterium mediated production of transgenic rice plants expressing a chimeric $\square$-amylase promoter / $\square$ glucouronidase gene. Plant Mol. Biol., 22: 491-506.

Cheng, C., R. K. Sardana and I. Altosaar.1998. In Methods in Biotechnology: Recombinant proteins from plants. (eds Cunningham C. and Porter, A. J. R.), Humana Press Inc., New Jersey, pp. 1-10.

Cheng, M., B. A. Lowe, T.M. Spencer, X. D. Ye and C. L. Armstrong. 2004. Factors influencing Agrobacterium - mediated transformation of monocotyledonous species. In vitro Cellular and Develop. Bio. Pl.., 40 (1): 31-45.

Cheng, M., J. E. Fry, S. Pang, I. Zhou, C. Hironaka and D. R. I. Duncan, T. W. L. Corner and Y. Wang. 1997. Genetic transformation of wheat mediated by Agrobacterium tumefaciens. Plant Physiol., 115: 971-980.

Cheng, X. Y., R. Sardana, H. Kaplan and I. Altosaar. 1998. Agrobacterium transformed rice plants expressing synthetic cry $1 \mathrm{~A}$ (b) and cry IA(c) genes are highly toxic to striped stem borer and yellow stem borer. Proc. Natl. Acad. Sci., USA. 95: 2767-2772.

Dong, J., W. Teng., W. G. Buchholz and T. C. Hall. 1996. Agrobacterium - mediated transformation of javanica rice. Mol. Breed., 2: 267-276.

FAOSTAT data, 2005. www.Fao.com.

Gatehouse, A. M. R. 1999. Biotechnological applications of plant genes in the production of insect resistant crops. In: Global plant genetic resources for insect resistant crops. (S.S. eds. Clement, S. L. and Quisenberry), CRC Press LLC, USA. P. 263-280.

Hi ei, Y., S. Ohta, T. Komari and T. Kumashiro. $1994 . \quad$ Efficient transformation of rice (Oryza sativa L.) mediated by Agrobacterium and sequence analysis of the boundaries of the T-DNA. Plant J., 6: 271-282.

Hi ei, Y., S. Otha., T. Komari and T. Kubo. C. 1997. Transformation of rice mediated by Agrobacterium tumefaciens. Plant Mol. Biol., 35: 205-218.

Hoque, M.E., J.W. Mansfield and M.H. Bennett. 2005. Agrobacterium-mediated transformation of indica rice genotypes: an assessment of factors affecting the transformation efficiency. Plant Cell. Tiss.Org. Culture., 82: 45-55.

Ishida, Y., S. H. Saito, S. Ohta, Y. Hiei, T. Komari and T. Kumashiro. 1996. High efficiency transformation of maize (Zea mays L.) mediated by Agrobacterium tumefaciens. Nature Biotech., 14: 745750.

Jain. R.K and S. Jain. 2000. Transgenic strategies for genetic improvement of Basmati rice. Indian J. of Experimental Biology, 38(1) pp -6-17.

Jefferson, R. A. 1987. Assaying chimeric genes in plants: The GUS gene fusion system. Plant Mol. Biol. Rep., 5: 387405.

Khush, G. S. and P. S. Virk. 2000. Rice Breeding Achievement and future strategies. Crop Improv., 27: 115-144.

Komari, T., Y. Hiei, Y. Saito, N. Murai and T. Kumashiro. 1996. Vectors carrying two separate T-DNAs for cotransformation of higher plants mediated by Agrobacterium tumefaciens and segregation of transformation free from selection markers. Plant J. 10: 165-174.

Kumar, K. K., S. Maruthasalam, M. Loganathan, D. Sudhakar and P. Balasubramanian. 2005. An improved 
Agrobacterium- mediated transformation protocol for recalcitrant elite indica rice cultivars. Pl. Mol. Bio. Rep., 23: 67-73.

Mahendranath G, T. Krishnakanth Yadav, P. Jagadish, M. Raghurami Reddy, S.M. Balachandran, E.A. Siddiq, K.N. Yamini and Anuradha G. 2018. Standardization of Agrobacterium mediated genetic transformation in Indica rice $\mathrm{cv}$ BPT-5204.Annals of Plant Sciences 7(2) pp. 2037-2041.

Malabika Roy, Rajender Kumar Jain, Jai Singh Rohila and Ray Wu. 2000. Production of agronomically superior transgenic rice plants using Agrobacterium transformation methods. Present status and future perspectives. Curr. Sci., 79 (7): 954-959.

Murashige, T. and F. Skoog. 1962. A revised medium for rapid growth and bioassay with tobacco tissue cultures. Physiol. Plantarum., 15: 473-497.

Opabode, J.T. 2006. Agrobacteriummediated transformation of plants: emerging factors that influence efficiency. Biotech and Mol Bio Rev. 1(1): pp.12-20.

Pipatpanukul, T., S.Bunnag, P. Theera kulpisut and M. Kostittrakul. 2004. Transformation of indica rice (Oryza sativa L.) cv. RD 6 mediated by Agrobacterium tumefaciens. Songklanakarin. J. Sci. Technol., 26 (1): 1-12.

Raineri, D. M., P. Bottino, M. P. Gordon and E. W. Nester. 1990. Agrobacterium mediated transformation of rice (Oryza sativa L.). Biotech., 8: 33-38.

Ramana Rao, M. V. and G. J. Narashimha Rao. 2007. Agrobacterium - mediated transformation of indica rice under acetosyringone-free conditions. Transgenic Note., 24: 507-511.

Rashid, H., S. Yokoi, K. Toriyama and K. Hinata. 1996. Transgenic plant production mediated by Agrobacterium in indica rice. Plant Cell Rep., 15: 727730.

Saharan, V., R. C. Yadav, N. R. Yadav and K. Ram. 2004. Studies on improved Agrobacterium - $\quad$ mediated transformation in two indica rice (Oryza sativa L.). African J. Biotech., 3(11): 572-575.

Tyagi, H., S. Rajasubramanian and I. Dasgupta. 2007. Regeneration and Agrobacterium - $\quad$ mediated transformation of a popular indica rice variety, ADT 39. Curr. Sci. 99 (5): 678683.

Visarada, K. B. R. S., M. Sailaja and N. P. Sarma. 2002. Effect of callus induction media on morphology of embryogenic calli in rice genotypes. Biol. Plant., 45: 495-502.

Visarada, K.B.R.S. and N.P. Sarma. 2004. Transformation of indica rice through particle bombardment: factors influencing transient expression and selection. Biologia Plantarum, 48 (1): 25-31.

Wang, M. B., Z. Y. Li, N. M. Upadhyaya, R. I. S. Brettell and P. M. Waterhouse. 1997. Intron mediated improvement of a selectable marker gene for plant transformation using Agrobacterium tumefaciens. J. Genet. Plant. Breed., 51: 25-334.

Weir, B., X. Gu, M. B. Wang, N. Upadhaya, A. R. Elliott and R. I. S. Brettell. 2001. Agrobacterium tumefaciens - mediated transformation of an elite Australian barley cultivar with virus resistance and reporter genes. Aust. J. Plant. Physiol., 28: 149-156.

Wu, H., A. C. Mccormac, M. C. Elliott and D. F. Chen. 1998. Agrobacterium mediated stable transformation of cell suspension cultures of barley (Hordeum vulgare). Plant Cell Tiss. Ogan. Cult., 54: 161-171. 
Wu, H., C. Sparks, B. Amoah and H. D. Jones. 2003. Factors influencing successful Agrobacterium - mediated genetic transformation of wheat. Plant Cell Rep., 21: 659-668.

Yara, A., M. Otani, K. Kusumi, O. Matsuda, T. Shimada and K. Iba. 2001. Production of transgenic japonica rice (Oryza sativa L.) cultivar. Taichung 65, by the Agrobacterium - mediated method. Plant Biotech., 18 (4): 305-310.

Zhang, W. S., Subbarao, P. Addae, A.Shen, C. Armstrong, V. Peschke and L. Gilbertson. 2003. Cre/lox mediated gene excision in transgenic maize (Zea mays L.) Plants. Theor. Appl. Genet., 107: 1157-1168.

\section{How to cite this article:}

Aananthi, N. and Anandakumar, C.R. 2018. Genetic Transformation in Aromatic Indica Rices Mediated by Agrobacterium tumefaciens. Int.J.Curr.Microbiol.App.Sci. 7(12): 3458-3487. doi: https://doi.org/10.20546/ijcmas.2018.712.394 